\title{
Energy and Electron Transfer in Enhanced Two-Photon- Absorbing Systems with Triplet Cores
}

\author{
Olga S. Finikova ${ }^{\dagger}$, Thomas Troxler ${ }^{\ddagger}$, Alessandro Senes ${ }^{\dagger}$, William F. DeGrado ${ }^{\dagger}$, Robin M. \\ Hochstrasser ${ }^{\ddagger}$, and Sergei A. Vinogradov ${ }^{\star}, \dagger$ \\ $\dagger$ Department of Biochemistry and Biophysics, University of Pennsylvania, Philadelphia, Pennsylvania 19104 \\ $\$$ Department of Chemistry, University of Pennsylvania, Philadelphia, Pennsylvania 19104
}

\begin{abstract}
Enhanced two-photon-absorbing (2PA) systems with triplet cores are currently under scrutiny for several biomedical applications, including photodynamic therapy (PDT) and two-photon microscopy of oxygen. The performance of so far developed molecules, however, is substantially below expected. In this study we take a detailed look at the processes occurring in these systems and propose ways to improve their performance. We focus on the interchromophore distance tuning as a means for optimization of two-photon sensors for oxygen. In these constructs, energy transfer from several 2PA chromophores is used to enhance the effective 2PA cross section of phosphorescent metalloporphyrins. Previous studies have indicated that intramolecular electron transfer (ET) can act as an effective quencher of phosphorescence, decreasing the overall sensor efficiency. We studied the interplay between 2PA, energy transfer, electron transfer, and phosphorescence emission using Rhodamine B-Pt tetrabenzoporphyrin (RhB-PtTBP) adducts as model compounds. 2PA cross sections $\left(\sigma_{2}\right)$ of tetrabenzoporphyrins (TBPs) are in the range of several tens of GM units (near 800 $\mathrm{nm}$ ), making TBPs superior 2PA chromophores compared to regular porphyrins ( $\sigma_{2}$ values typically 1-2 GM). Relatively large 2PA cross sections of rhodamines (about $200 \mathrm{GM}$ in $800-850 \mathrm{~nm}$ range) and their high photostabilities make them good candidates as 2PA antennae. Fluorescence of Rhodamine B $\left(\lambda_{\mathrm{fl}}=590 \mathrm{~nm}, \phi_{\mathrm{fl}}=0.5 \mathrm{in} \mathrm{EtOH}\right)$ overlaps with the Q-band of phosphorescent PtTBP $\left(\lambda_{\mathrm{abs}}=615 \mathrm{~nm}, \epsilon=98000 \mathrm{M}^{-1} \mathrm{~cm}^{-1}, \phi_{\mathrm{p}} \sim 0.1\right)$, suggesting that a significant amplification of the 2PA-induced phosphorescence via fluorescence resonance energy transfer (FRET) might occur. However, most of the excitation energy in RhB-PtTBP assemblies is consumed in several intramolecular ET processes. By installing rigid nonconducting decaproline spacers $\left(\mathrm{Pro}_{10}\right)$ between $\mathrm{RhB}$ and PtTBP, the intramolecular ETs were suppressed, while the chromophores were kept within the Förster $r_{0}$ distance in order to maintain high FRET efficiency. The resulting assemblies exhibit linear amplification of their 2PA-induced phosphorescence upon increase in the number of 2PA antenna chromophores and show high oxygen sensitivity. We also have found that PtTBPs possess unexpectedly strong forbidden $\mathrm{S}_{0} \rightarrow \mathrm{T}_{1}$ bands $\left(\lambda_{\max }=762 \mathrm{~nm}, \epsilon=120 \mathrm{M}^{-1} \mathrm{~cm}^{-1}\right)$. The latter may overlap with the laser spectrum and lead to unwanted linear excitation.
\end{abstract}

\section{Introduction}

Two-photon laser scanning microscopy (2P LSM), pioneered by Denk and Webb in $1990{ }^{2}$ has become one of the most popular tools in modern neuroscience and cellular research. ${ }^{3} 2 \mathrm{P}$ LSM is based on the multiphoton-absorption phenomenon, ${ }^{4}$ which presents considerable

\footnotetext{
*Corresponding author. E-mail: vinograd@mail.med.upenn.edu.

Supporting Information Available: Experimental details, synthetic procedures, and characterization data for the compounds described in this paper; complete ref $9 \mathrm{~b}$. This material is available free of charge via the Internet at http://pubs.acs.org
} 
interest for such applications as high-density data storage, ${ }^{5}$ optical limiting, ${ }^{6}$ and photodynamic therapy (PDT), ${ }^{7}$ attracting more and more chemists to the search for new multiphoton-absorbing materials. Typically, two-photonabsorption (2PA) cross sections $\left(\sigma_{2}\right)$ 1 of commonly used organic dyes are small and only in a few cases (e.g., rhodamines) reach moderate values, e.g., hundreds of Göppert-Mayer (GM) units. ${ }^{8}$ A number of systems with enhanced 2PA cross sections have been proposed in recent years, ${ }^{9-14}$ and rational ways of designing 2PA molecules are being developed. $9 \mathrm{a}, 15$

Although large $\sigma_{2}$ values are generally desirable for all 2PA optical probes, imaging with fluorescent agents, which typically possess high quantum yields, can be accomplished even when they exhibit low 2PA cross sections. On the contrary, for emitters with intrinsically low quantum yields and/or long excited-state lifetimes, such as phosphorescent probes, amplification of 2PA is an absolute requirement. Phosphorescent probes are useful for biological measurements because their long lifetimes make them extremely sensitive to a variety of quenching processes. One such process involves oxygens-a key component of the biological energy metabolism. Oxygen sensing in vivo by phosphorescence 16,17 is a technology with many potential uses in physiological and medical research, ${ }^{18}$ including applications in microscopy and imaging. ${ }^{19}$ Combining phosphorescence quenching with $2 \mathrm{P}$ LSM would provide a new technique for high-resolution imaging of oxygen with intrinsic three-dimensional capabilitys - a useful tool for studying neuronal activation, evaluating heterogeneity of hypoxia in tumors, and monitoring metabolic processes inside living cells.

Phosphorescent probes for biological oxygen sensing are usually based on Pd or Pt porphyrins, whose intersystem crossing rates and phosphorescence quantum yields are high and whose submillisecond triplet lifetimes ensure their excellent oxygen sensitivity. ${ }^{20}$ Unfortunately, 2PA cross sections of metalloporphyrins and other useful phosphorescent dyes, such as $\mathrm{Ru}^{2+}(\text { bpy })_{3}$ and similar complexes, ${ }^{17}$ are typically very low, no more than several GM units. 21,22 In centrosymmetrical molecules, selection rules for one-photon (1P) and $2 \mathrm{P}$ transitions are mutually exclusive, and excited states corresponding to the strongly allowed Soret and Qband transitions of metalloporphyrins have correspondingly weak $2 \mathrm{PA}$ cross sections. ${ }^{23}$ Recently, much attention has been focused on tetrapyrroles with increased 2PA cross sections. 2PA of porphyrins can be increased by asymmetrical substitution ${ }^{24}$ or through porphyrin conjugation into oligomers and arrays. ${ }^{10}$ Some of these new materials appear to be effective in singlet oxygen sensitization; however, no explicit data have been reported on their triplet quantum yields. Similarly, no data on phosphorescence of 2PA porphyrins have been published, and it is not clear how perturbation of the porphyrin electronic system would affect the emissivity of its triplet states. In addition, some data suggest that increase in the length of porphyrin arrays causes a decrease in their intersystem crossing yields and hampers triplet production. 25

An alternative approach to amplification of 2PA signals from porphyrins without directly altering their electronic properties has recently been proposed as a means of constructing phosphorescent oxygen sensors ${ }^{26}$ and 2PA PDT agents. ${ }^{27}$ The idea behind this approach is to harvest the excitation energy by an electronically separate 2PA antenna, which then would pass the excitation to the porphyrin via intramolecular Förster-type resonance energy transfer (FRET). ${ }^{28}$ Intersystem crossing (isc) within the porphyrin then generates the triplet state, which decays back to the ground state by either emitting a photon (phosphorescence) or sensitizing oxygen. In phosphorescent sensors, the rate of oxygen diffusion to the core is regulated by dendritic encapsulation, while the dendrimer termini control the probe's biodistribution. ${ }^{18 \mathrm{e}, 29}$ Several model compounds have been constructed in order to evaluate this design, proving that the approach is feasible and promising. However, certain difficulties have been identified as well. 
First of all, amplification of the core functions-whether it is emission or singlet oxygen sensitizations- did not appear to scale linearly with the 2PA cross section of the antenna. Instead, structures with built-in enhancement pathways showed lower performance than theoretically expected from their estimated 2PA action cross sections. Second and more importantly, electron transfer (ET) between the antenna and the triplet-state core was identified as an unwanted but extremely effective route for the triplet quenching. Preventing the ET between the core and the 2PA antenna would either require chromophores incapable of electron exchange or, more realistically, placing the chromophores at such a distance from one another that the ET would be diminished, while the FRET would be maintained at its highest possible rate. Such distance tuning should be possible because of the difference in the rate dependences for the Förster-type energy transfer ${ }^{30,31}$ and electron transfer. ${ }^{32,33}$

Positioning chromophores at optimal distances, carefully selected during the course of evolution, is the key to the outstanding performance of natural photosynthetic systems, which employ combinations of energy- and electron-transfer reactions for energy transduction and conservation. ${ }^{34}$ Not surprisingly, these processes have been studied by many researchers using a variety of synthetic models, and the literature covering this subject is very extensive. 32,35 , 36 In contrast, there are relatively few reports on the 2 PA-induced FRET $27,37,38$ and none, to our knowledge, on the combination of 2PA, FRET, and ET.

In this paper we studied model 2PA antenna-triplet core dyads to identify undesirable photoinduced ET processes and to evaluate their distance dependence. We then synthesized assemblies in which the antenna and the core were separated by nonconducting polyproline linkers at distances where the ETs were prevented but the energy transfer remained highly efficient. Finally, enhancement of the core 2PA-induced phosphorescence as a function of the number of antenna chromophores was measured in femtosecond regime. As a result, guidelines for design of optimized antenna-triplet core 2PA systems for biological applications were developed.

\section{Results and Discussion}

\section{Functional Components of the Device}

The first reported 2PA-amplified phosphorescent sensors consisted of Pt mesotetraarylporphyrins (PtP) as triplet cores and commercial Coumarin-343 (C343) as 2PA antennae. ${ }^{26}$ The FRET from C343 onto PtP was efficient ( $\left.~ 80 \%\right)$, and upon femtosecond (fs) excitation in the region of $800 \mathrm{~nm}$ an increase in the core phosphorescence was readily observed. However, amplification in 2PA-induced phosphorescence for all PtP-C343 systems was modest, in part due to the relatively low $2 \mathrm{PA}$ cross section of $\mathrm{C} 343\left(\sigma_{2} \sim 20 \mathrm{GM}\right)$.

In this study we turned our attention to rhodamines, which have $2 \mathrm{PA}$ cross sections of about $200 \mathrm{GM}$ in the $840 \mathrm{~nm}$ range $8 \mathrm{a}, 39$ and potentially can perform as effective $2 \mathrm{PA}$ antennae. Rhodamine B (RhB, Figure 1 ) fluoresces near $\lambda_{\max } \approx 590 \mathrm{~nm}$ with the quantum yield $\phi_{\mathrm{fl}}=$ $0.5^{40,41}$ and is known for its high photostability. Functionalized derivatives of RhB are readily accessible via the recently reported chemistry. 42

To match the emission of RhB for the most efficient transfer of the excitation energy, we chose $\mathrm{Pt}$ meso-tetraaryltetrabenzoporphyrins (PtTBP, Figure 1) to be the triplet cores. Pt and Pd tetrabenzoporphyrins exhibit strong phosphorescence at ambient temperatures, ${ }^{20 \mathrm{~d}, 43}$ and their NIR absorption bands warrant their use as probes for in vivo oxygen imaging. $19^{\mathrm{c}, \mathrm{d}, 29 \mathrm{c}} \mathrm{A}$ versatile method of synthesis of $\pi$-extended porphyrins has recently been developed, ${ }^{44}$ making it possible to place various functional groups on the TBP macrocycle. The absorption Q-band of PtTBP $2\left(\lambda_{\max }=615 \mathrm{~nm}, \epsilon=98000 \mathrm{M}^{-1} \mathrm{~cm}^{-1}\right)$ overlaps significantly with the fluorescence of RhB (Figure 1), suggesting efficient FRET between these two molecules. Assuming random 
orientation of transition dipoles $\left(\kappa^{2}=2 / 3\right)$ and a refractive index of $1.36(\mathrm{EtOH})$, the Förster distance $r_{0}$ for the RhB-PtTBP pair was estimated to be $53 \AA .45$

An important property of meso-tetraaryltetrabenzoporphyrins, especially in the view of the present application, is their high nonplanarity. TBPs and their metal derivatives possess severely saddled structures. ${ }^{44 b, 46}$ As a result, their ground-state wave functions lack centers of symmetry, and that should cause an increase in their 2PA cross sections. Some data in the literature indeed mention relatively large $\sigma_{2}$ values for TBPs, e.g., about $90 \mathrm{GM}\left(\lambda_{\mathrm{ex}}=800\right.$ $\mathrm{nm}$ ) for $\mathrm{Zn}$ meso-tetraaryltetrabenzoporphyrin. ${ }^{21 \mathrm{~b}}$ Interestingly, in spite of strong nonplanarity, TBPs and other $\pi$-extended porphyrins exhibit high emission quantum yields, $20 \mathrm{~d}, 29 \mathrm{c}, 43,44$ while other nonplanar porphyrins are practically nonemissive, as a result of enhanced internal conversion. ${ }^{47}$

\section{RhB-PtTBP Adducts with Short Spacers}

The simplest bichromophoric assemblies studied in this work were RhB-PtTBP adducts, in which the antenna $(\mathrm{RhB})$ and the core (PtTBP) were present in 1:1 ratio and connected via short nonconjugated linkers. Two such molecules, $\mathbf{5}$ and $\mathbf{6}$, are shown in Scheme 1, and detailed description of their synthesis can be found in the Supporting Information.

Isolation and handling of $\mathbf{5}$ proved difficult. This compound degrades rapidly in concentrated solutions at ambient temperatures and decomposes, although slowly, even when shielded from ambient light. Pure $\mathbf{5}$ could be preserved by freezing its solutions immediately after chromatography. Adduct $\mathbf{6}$ turned out to be more stable than $\mathbf{5}$, although its partial decomposition was revealed by the decrease in its $\mathrm{RhB}$ absorption when the compound was exposed to ambient light or handled at elevated temperatures.

A. Spectroscopy-The photophysical data for all the compounds described in this paper are summarized in Table 1. The absorption spectra of adducts $\mathbf{5}$ and $\mathbf{6}$ and of an equimolar mixture of reference compounds $1 \mathbf{a}$ and $\mathbf{3 a}$ are nearly identical, suggesting no interactions between the chromophores in their ground states (Figure 2A).

The emission spectra shown in Figure 2B were recorded upon excitation at $\lambda_{\mathrm{ex}}=520 \mathrm{~nm}$, where the absorption of PtTBP is low, whereas the absorption of $\mathrm{RhB}$ is significant. The intramolecular FRET between RhB and PtTBP in adducts 5 and $\mathbf{6}$ was expected to quench the fluorescence of $\operatorname{RhB}\left(\lambda_{\max }=587 \mathrm{~nm}\right)$, but at the same time amplify the phosphorescence of $\operatorname{PtTBP}\left(\lambda_{\max }=770 \mathrm{~nm}\right)$. Instead, both fluorescence and phosphorescence in $\mathbf{5}$ and $\mathbf{6}$ appeared to be almost entirely quenched (Figure $2 \mathrm{~B}$ ). Direct excitation into the porphyrin Q-band $\left(\lambda_{\mathrm{ex}}\right.$ $=611 \mathrm{~nm}$ ), bypassing the RhB absorption and the FRET, revealed that the phosphorescence quantum yields of $\mathbf{5}\left(\phi_{\mathrm{p}}<0.001\right)$ and $\mathbf{6}\left(\phi_{\mathrm{p}}=0.001\right)$ were decreased by $98-99 \%$ compared to the reference compound $1 \mathbf{a}\left(\phi_{\mathrm{p}}=0.083 \mathrm{in} \mathrm{EtOH}\right)$. Quenching due to intermolecular aggregation was ruled out since the replacement of solvents $\left(\mathrm{CH}_{2} \mathrm{Cl}_{2}, \mathrm{DMF}\right)$ and/or dilution of samples (10-100 times) had almost no effect on the phosphorescence, and no evidence of aggregation was observed in the absorption spectra (Figure 2A). Such strong attenuation of the emission could be explained only by the presence of intramolecular quenching pathways in RhB-PtTBP adducts. The most plausible mechanisms would involve $\mathrm{RhB} \leftarrow$ PtTBP triplet-triplet energy transfer and intramolecular electron transfer(s) (ET), competing with the phosphorescence.

Both intramolecular and intermolecular ET between porphyrins and xanthene dyes have been described in the literature, ${ }^{50}$ although, to the best of our knowledge, no studies involving phosphorescent porphyrins have been reported. On the other hand, literature data suggest that the $\mathrm{T}_{1}-\mathrm{S}_{0}$ gap for $\mathrm{RhB}$ is $1.86 \mathrm{eV}(667 \mathrm{~nm}),{ }^{51}$ whereas phosphorescence of PtTBP occurs at $770 \mathrm{~nm}(1.61 \mathrm{eV})$, making $\mathrm{RhB} \leftarrow$ PtTBP triplet-triplet exchange energetically unfavorable. Thus, the ET between the excited PtTBP and RhB in its ground state is the most probable 
mechanism of the phosphorescence quenching. In principle, two such ETs are possible for RhB-PtTBP systems: one involving the PtTBP singlet state $S_{1}$ and competing with $S_{1} \rightarrow T_{1}$ intersystem crossing (isc) and another involving the PtTBP triplet state $\mathrm{T}_{1}$ and competing with phosphorescence itself. Below, we refer to these $\mathrm{ETs}$ as $\mathrm{ET}_{\mathrm{PtTBP}(\mathrm{S})}$ and $\mathrm{ET}_{\mathrm{PtTBP}(\mathrm{T})}$, respectively.

Assuming the pure Förster model and the distance between the reactants of $13 \AA, 52$ the rate of the energy transfer in $\mathbf{5}$ was estimated to be $k_{\mathrm{FRET}}=2.5 \times 10^{12} \mathrm{~s}^{-1}$. 45 At such a rate the residual emission from $\mathrm{RhB}$, whose singlet-state lifetime in the absence of quenching is 1.85 ns (Table $1, \mathbf{3 a}$ ), would be truly negligible. For example, in the case of $\mathbf{5}$, the predicted quantum yield of $\mathrm{RhB}$ fluorescence is about $10^{-4}$, whereas in our experiments it was 0.004 (Table 1, 5). The observed discrepancy suggests that either rigid structural features are present in dyads 5 and $\mathbf{6}$, which cause a major decrease in the value of the orientation factor $\kappa^{2}$, or contaminant fluorescence from an impurity, e.g., unbound $\mathrm{RhB}$, is the source of the increased apparent fluorescence quantum yield. The intensity of the contaminant fluorescence, however, is very small and does not affect our calculations (see below).

Energy-transfer efficiencies in $\mathbf{5}$ and $\mathbf{6}$ were estimated by comparing their excitation $\left(\lambda_{\mathrm{em}}=\right.$ $770 \mathrm{~nm}$ ) and absorption spectra (Figure 2C), scaled to the same value at the Q-band maximum $\left(\lambda_{\mathrm{ex}}=611 \mathrm{~nm}\right) .53$ In such measurements, an exact match between the absorption and excitation spectra would signify energy transfer with $100 \%$ efficiency. The intensities of the RhB bands $\left(\lambda_{\max }=563 \mathrm{~nm}\right)$ in the excitation spectra of 5 and $\mathbf{6}$ reveal that only $21 \%(5)$ and $83 \%(6)$ of the excitation energy absorbed by RhB fragments is transferred to PtTBP. At the same time, $\mathrm{RhB}$ fluorescence $\left(\lambda_{\max }=587 \mathrm{~nm}\right)$ in $\mathbf{5}$ and $\mathbf{6}$ is negligible compared to the fluorescence of reference compound 3a, taken at the same molar concentration (Figure $2 \mathrm{~B}$ ). Therefore, approximately $79 \%$ (5) and $17 \%$ (6) of the absorbed energy is consumed in some other process, which in this case is probably ET involving the RhB excited singlet state. This ET will be referred to as $\mathrm{ET}_{\mathrm{RhB}(\mathrm{S})}$.

The proposed energy-/electron-transfer pathways in RhB-PtTBP systems are shown in Scheme 2. The pathway preferred for our application is shown in the box, and the charge-separated state (CS), formed as a result of the electron transfer, is designated as [RhB-PtTBP] $]_{\mathrm{CS}}$. Processes $\mathrm{ET}_{\mathrm{RhB}(\mathrm{S})}, \mathrm{ET}_{\mathrm{PtTBP}(\mathrm{S})}$, and $\mathrm{ET}_{\mathrm{PtTBP}(\mathrm{T})}$ compete with the preferred pathway by interfering respectively with the FRET, with the intersystem crossing, and with the phosphorescence emission, all leading to the same state $[\mathrm{RhB}-\mathrm{PtTBP}]_{\mathrm{CS}}$. The pathways of annihilation of $[\mathrm{RhB}-\mathrm{PtTBP}]_{\mathrm{CS}}$ remained unidentified and are not shown.

Unfortunately, our attempts to obtain a spectroscopic signature of the charge-separated state $[\mathrm{RhB}-\mathrm{PtTBP}]_{\mathrm{CS}}$ turned out to be unsuccessful (see Supporting Information for details). The transient spectrum of 5 in the window 400-650 nm (set by the limits of the instrument) was entirely dominated by the broad $\mathrm{T}_{1} \rightarrow \mathrm{T}_{2}$ band of PtTBP $\left(\lambda_{\max }=463 \mathrm{~nm}\right)$. Similar bands were reported previously for Pd tetraaryltetrabenzoporphyrins. ${ }^{43 \mathrm{c}}$ It is possible that the absorption of the CS state was too weak to be seen on the background of this strong band. Photoinduced electron transfer between RhB and PtTBP nevertheless appears to be the most likely pathway competing with emission in the studied dyads.

B. Electron Transfer-The directionality of the photoinduced ET in RhB-PtTBP adducts could be resolved by substituting spectroscopic and electrochemical data into the Rehm-Weller equation: 54

$$
\Delta G_{\mathrm{ET}}=E_{\mathrm{OX}}(\mathrm{D})-E_{\mathrm{red}}(\mathrm{A})-\Delta E_{00}+w
$$

where $\Delta G_{\mathrm{ET}}$ is the driving force, $E_{\mathrm{Ox}}(\mathrm{D})$ is the oxidation potential of the donor, $E_{\mathrm{red}}(\mathrm{A})$ is the reduction potential of the acceptor, $\Delta E_{00}$ is the excitation energy of the photoexcited component 
(donor or acceptor), and $w=w_{\mathrm{P}}-w_{\mathrm{R}}$ is the work term, consisting of the Coulombic energies of reactants $\left(w_{\mathrm{R}}\right)$ and products $\left(w_{\mathrm{P}}\right)$.

The values for $\mathbf{1 a}$ are $E_{\text {ox }}^{1}=+0.75$ and $\mathrm{V} E_{\text {red }}^{1}=-1.3 \mathrm{~V}$ vs SCE. In the case of $\mathbf{3 a}$, a reversible reduction wave was observed at $E_{\mathrm{red}}=-0.8 \mathrm{~V}$, while the oxidation was irreversible and occurred at approximately $E_{\mathrm{ox}}=1.1 \mathrm{~V}$. These data are consistent with the earlier reported values for Rhodamine B in EtOH solutions. ${ }^{55}$ The excitation energy for RhB was estimated from the intersection of its normalized absorption and fluorescence spectra $\left(\lambda=565 \mathrm{~nm}, \Delta E_{00}=2.2\right.$ $\mathrm{eV})$. The value for the PtTBP $\pi-\pi^{*}$ triplet was derived from the phosphorescence maximum $\left(\lambda_{\max }=772 \mathrm{~nm}, \Delta E_{00}(\mathrm{~T})=1.61 \mathrm{eV}\right)$. The energy of the PtTBP singlet state could be derived from the phosphorescence maximum and the magnitude of the singlet-triplet splitting ( $2 J=$ $0.38 \mathrm{eV})$, determined from the difference between the $\mathrm{S}_{0} \rightarrow \mathrm{S}_{1}\left(\lambda_{\max }=611 \mathrm{~nm}\right)$ and $\mathrm{S}_{0} \rightarrow$ $\mathrm{T}_{1}\left(\lambda_{\max }=762 \mathrm{~nm}\right.$; see below) absorption maxima: $\Delta E_{00}(\mathrm{~S})=1.99 \mathrm{eV}$.

The energy diagram of the ET in RhB-PtTBP systems and the corresponding frontier orbital levels are shown in Figure 3.

The ET from RhB onto PtTBP appears to be endergonic $\left(\Delta G_{\mathrm{ET}}>0\right)$, in spite of the small favorable Coulombic work term $(w=-0.06 \mathrm{eV}),{ }^{56}$ which is due to the stabilizing interaction between PtTBP anion and $\mathrm{RhB}$ dication. (RhB is a cation by itself, and upon the ET onto PtTBP its net charge becomes +2 ).

The ET in the opposite direction, from PtTBP onto RhB, is exergonic $\left(\Delta G_{\mathrm{ET}}<0\right)$ for all the excited states, and the work terms in all three cases are close to zero. As discussed above, $\mathrm{ET}_{\mathrm{RhB}(\mathrm{S})}\left(\mathbf{1} ; \Delta G_{\mathrm{ET}}=-0.65 \mathrm{eV}\right)$ competes effectively with the FRET. Assuming the theoretical rate of the FRET as calculated above $\left(k_{\mathrm{FRET}}=2.5 \times 10^{12} \mathrm{~s}^{-1}\right)$ and considering that ratios between efficiencies of $\mathrm{ET}_{\mathrm{RhB}(\mathrm{S})}$ and FRET in dyads $\mathbf{5}$ and $\mathbf{6}$ are 3.76 and 0.20 , respectively $\left(\phi_{\mathrm{ET} 1}(\mathbf{5}) / \phi_{\mathrm{FRET}}(\mathbf{5})=79 / 21 \approx 3.76\right.$ and $\left.\phi_{\mathrm{ET} 1}(\mathbf{6}) / \phi_{\mathrm{FRET}}(\mathbf{6})=17 / 83 \approx 0.20\right)$, we arrive at the upper bound estimate for the rate of $\mathrm{ET}_{\mathrm{RhB}(\mathrm{S})}$, i.e., $k_{\mathrm{RhB}(\mathrm{S})}=10^{12}-10^{13} \mathrm{~s}^{-1}$.

Following the FRET, another ET (2; $\mathrm{ET}_{\mathrm{PtTBP}(\mathrm{S})}$ ), leading to the same charge-separated state is initiated, with the driving force of about $0.2 \mathrm{eV}$ less than that of $\mathrm{ET}_{\mathrm{RhB}(\mathrm{S})}$. This ET competes directly with the intersystem crossing within the PtTBP macrocycle. The existing photophysical data on Pt porphyrins $20^{\mathrm{a}, c, 57}$ indicate that intersystem crossing occurs in these molecules on a subpicosecond time scale. Therefore, $\operatorname{RhB}-\mathrm{PtTBP}(\mathrm{T})$ is most certainly generated at a rate comparable to that of $\mathrm{ET}_{\mathrm{PtTBP}(\mathrm{S})}$.

Once formed, the state RhB-PtTBP(T) in turn undergoes the electron-transfer reaction ${ }_{58}^{\mathrm{ET}_{\mathrm{PtBP}}(\mathrm{T})}(3)$. Since electron-transfer processes generally occur with conservation of spin, 58 the processes $\mathrm{ET}_{\mathrm{PtTBP}(\mathrm{S})}$ and $\mathrm{ET}_{\mathrm{RhB}(\mathrm{S})}$ lead to the same singlet biradical charge-separated state, designated in Figure $3 \mathrm{~A}$ as $\left[\mathrm{RhB}^{-}-\mathrm{PtTBP}^{+}\right]_{\mathrm{CS}}(\mathrm{S})$. On the contrary, $\mathrm{ET}_{\mathrm{PtTBP}(\mathrm{T})}$, originating in the triplet state, gives the triplet pair of doublets $\left[\mathrm{RhB}^{-}-\mathrm{PtTBP}^{+}\right]_{\mathrm{CS}}(\mathrm{T})$. The exchange energy $(2 J)$ for these transient species is not known, but in general $2 J$ values are much smaller for CS states than for individual chromophores. ${ }^{58}$ For the purposes of our analysis we assumed that $2 J$ was $1 / 10$ of that for PtTBP, i.e., about $0.04 \mathrm{eV}$. This assumption results in the upper bound estimate for the driving force for $\mathrm{ET}_{\mathrm{PtTBP}(\mathrm{T})}$, i.e., $\Delta G_{\mathrm{ET}} \approx-0.1 \mathrm{eV}$.

A straightforward way to prevent unwanted quenching in antenna-triplet emitter complexes would be to reduce the driving force of the ET. It follows from Figure 3A and the Rehm-Weller formula that $\Delta G_{\mathrm{ET}}$ can be made less negative by either decreasing the reduction potential of the acceptor $(\mathrm{RhB})$ or by increasing the oxidation potential of the donor (PtTBP). At the same time, the HOMO-LUMO gaps of the donor and the acceptor should be kept close in order to maintain large spectral overlap integrals for maximally efficient FRET. Such redox tuning can in principle be accomplished changing the dye's peripheral substitution, i.e., using acceptor 
groups to increase $E_{\mathrm{OX}}$ and donor groups to decrease $E_{\text {red }} \cdot 35 \mathrm{~d} \sigma$-Donors and $\sigma$-acceptors would be preferred, as those are less likely to alter the spectroscopic properties. Nevertheless, it follows from the orbital diagrams (Figure 3B-D) that by raising the RhB's HOMO too high or lowering the PtTBP's HOMO too low the ET's direction can be reversed. In practice, precise adjustment of the potentials in order to eliminate the ET might become an extremely tedious task, given that the antenna and the emitter dyes already must satisfy a number of criteria, e.g., high 2PA cross section and strong phosphorescence. Therefore, having an additional mechanism for tuning the ET rates and thus maximizing the sensor performance would be highly desirable.

C. Distance Dependences-Electron-transfer theories predict that rates of intramolecular ET reactions decay exponentially with the distance $r$ between the donor and acceptor sites: $k_{\mathrm{ET}}=v \exp (-\beta r)$, where parameter $\beta$ is related to the magnitude of the electronic interaction between the donor and the acceptor and, therefore, is dependent on the nature of the linker between the donor and the acceptor; $v$ includes the terms dependent on the driving force $\Delta G_{\mathrm{ET}}$ and the reorganization energy $\lambda .32,33$ Considering that $\mathrm{ET}_{\mathrm{RhB}(\mathrm{S})}$ and $\mathrm{ET}_{\mathrm{PtTBP}(\mathrm{S})}$ in our scheme compete with very fast processes, i.e., FRET and intersystem crossing, reducing the efficiencies of these two ET reactions should be relatively easy. Indeed, increasing the separation between PtTBP and RhB by only three $\sigma$-bonds (6 vs 5) had a pronounced effect on the ratio of the $\mathrm{ET}_{\mathrm{RhB}(\mathrm{S})}$ and FRET quantum yields $\left(\phi_{\mathrm{RhB}(\mathrm{S})} / \phi_{\mathrm{FRET}}\right)$, changing it by as much as 18.4 times, from 3.76 to 0.20 . Using the expression for $k_{\mathrm{ET}}$ (above) and assuming that (1) at the separation between transition dipoles $r_{\text {FRET }}=13 \AA$ (as in 5) the FRET has its theoretical rate $\left(k_{\text {FRET }}=2.5 \times 10^{12} \mathrm{~s}^{-1}\right)$, (2) the edge-to-edge distance between RhB and PtTBP, corresponding to $r_{\mathrm{FRET}}=13 \AA$, is $r_{\mathrm{ET}}=7.5 \AA$; and (3) the increase in the separation $(\Delta r)$ going from 5 to 6 equals about $3.4 \AA$, 59 we obtain $\beta=5.4 \times 10^{7} \mathrm{~cm}^{-1}$ and $v=5.7 \times 10^{14} \mathrm{~s}^{-1}$. This value of $v$ appears to be unrealistically high, as typical pre-exponential factors $v$ in the distancedependence equation do not exceed $10^{13} \mathrm{~s}^{-1}$. 33 The error in our calculation is most likely caused by the overestimation of $k_{\mathrm{FRET}}$ for dyads $\mathbf{5}$ and $\mathbf{6}$, in which the distances between chromophores are quite short (10-15 $\AA$ ). As pointed out in a recent study, ${ }^{60}$ incomplete orientational averaging $\left(\kappa^{2}<2 / 3\right)$ often occurs in molecules connected by short saturated linkers, such as in our models $\mathbf{6}$ and especially $\mathbf{5}$. In addition, at short distances, Förster point-dipole approximation is inaccurate, and the rate of the Coulombic energy transfer must be evaluated by quantummechanical methods, which might result in rates lower than those predicted by the Förster model. 60

Taking this into account, we now assume that the preexponential factor in the case of $\mathrm{ET}_{\mathrm{PtTBP}(\mathrm{T})}$ is $10^{13} \mathrm{~s}^{-1}, 33$ and use parameter $\beta$ as determined for $\mathrm{ET}_{\mathrm{RhB}(\mathrm{S})}$. Considering that the rate of the phosphorescence emission of PtTBP 1a in the absence of oxygen is $k_{\text {phos }}=3.03$ $\times 10^{4} \mathrm{~s}^{-1}\left(\tau_{0}=33 \mu \mathrm{s}\right.$, Table 1$)$, we estimate that in order for the phosphorescence to be, e.g., 10 times more effective than quenching by the electron transfer $\left(k_{\mathrm{phos}} / k_{\mathrm{PtTBP}(\mathrm{T})}=10\right)$, the chromophores must be placed at a distance $r_{\text {phos }} \approx 40 \AA$. At this separation, FRET between $\mathrm{RhB}$ and PtTBP should have the rate of $2.9 \times 10^{9} \mathrm{~s}^{-1}$ and should be about 5.4 times more efficient than RhB fluorescence $\left(k_{\mathrm{fl}}=1 / \tau_{\mathrm{fl}}=5.4 \times 10^{8} \mathrm{~s}^{-1}\right)$. As a result, by separating the chromophores using nonconducting linkers as in $\mathbf{5}$ or $\mathbf{6}$ we should be able to gain significantly in the phosphorescence quantum yield while maintaining high efficiency of the FRET. The graphs illustrating these conclusions are shown in Figure 4 and the details of calculations are given in the Supporting Information. It also should be mentioned that at the separation $r_{\text {phos }}=$ $40 \AA$ the rate of electron transfer $\mathrm{ET}_{\mathrm{PtTBP}(\mathrm{S})}$ will constitute only a negligible fraction $\left(\sim 10^{-6}-10^{-7}\right)$ of the intersystem crossing rate within PtTBP molecule.

We would like to emphasize that the assumptions underlying our analysis are quite crude. First, as we already mentioned, Förster's theory might be inaccurate in predicting the energy-transfer rates for compounds with short spacers, as in $\mathbf{5}$ and $\mathbf{6}$. Second, considering the flexibility of 
the linkers and short distances, direct contacts in $\mathbf{5}$ and $\mathbf{6}$ might greatly facilitate ET processes and exceedingly high values for the parameter $\beta$, resulting in errors when extrapolating to longer distances. Finally, when calculating the distance at which the phosphorescence can effectively compete with $\mathrm{ET}_{\mathrm{PtTBP}(\mathrm{T})}$, we assumed that $v=10^{13} \mathrm{~s}^{-1}$ but used $\beta=5.4 \times 10^{7}$ $\mathrm{cm}^{-1}$ obtained for $\mathrm{ET}_{\mathrm{RhB}(\mathrm{S})}$. Therefore, the above discussion provides only a rough estimation of rates and distances; however, it demonstrates the principles of optimization of 2PA antennacore systems via distance tuning.

\section{RhB-PtTBP Adducts with Polyproline Spacers}

It is well-established that saturated spacers can act as "insulators" between donor and acceptor motifs, providing control over electron-transfer rates. The efficiency of this approach has been proven in a variety of models. ${ }^{33 \mathrm{a}}$ Chromophores used in the past to study the distance dependence of electron transfer include heme proteins with porphyrins containing $\mathrm{Zn}, \mathrm{Mg}, \mathrm{Cd}$, $\mathrm{Pt}$, and $\mathrm{Pd}$ and possessing long-lived triplet states ${ }^{61}$ as well as other triplet emitters. $33 \mathrm{a}$

To implement distance tuning in RhB-PtTBP dyads, we considered rigid oligoproline spacers. Oligoprolines $\left(\mathrm{Pro}_{n}\right)$ are known to form rigid spiral rods in solution 62 and have been employed previously as "spectroscopic rulers". ${ }^{60}, 62^{\mathrm{d}, \mathrm{h}}$ The peptide bond in oligoprolines can adopt either cis or trans conformation, with the helix translation step of $3.12 \AA$ (per proline unit) in fully trans conformation vs $1.85 \AA$ in fully cis conformation. ${ }^{2} \mathrm{~g}$ Optical rotatory dispersion (ORD), circular dichroism (CD), and NMR studies of oligoprolines $\mathrm{Pro}_{n}$ suggest that, for $n>$ 5 , the helix exists exclusively in trans conformation in most solvents (water, alcohol, acetic acid, DMSO, chloroform). ${ }^{62}$ For shorter oligoprolines $(n=2-4)$, the cis conformation is also present, especially in less-polar solvents, although trans conformation is still predominant.

Based on the analysis presented above, we chose to connect $\mathrm{RhB}$ and PtTBP by decaproline spacers $\left(\right.$ Pro $\left._{10}\right)$. In its fully trans conformation, Pro $_{10}$ is approximately $31 \AA$ Å long, and according to molecular modeling it should provide separation between RhB and PtTBP of about $42 \AA$ (Figure 5). This distance should be adequate for suppressing $\mathrm{ET}_{\mathrm{PtTBP}(\mathrm{T})}$.

RhB-Pro 10 conjugate 7 and dyads $\mathbf{8}$ and $\mathbf{9}$ are shown in Scheme 3, and their synthesis and characterization are described in detail in the Supporting Information.

Spectroscopy-The emission, excitation, and absorption spectra of compound $\mathbf{8}$, as well as of the reference compounds 1a and 3a, are shown in Figure 6. As expected, the absorption spectrum of $\mathbf{8}$ matches that of $\mathbf{5}$ and presents nearly a superposition of the spectra of the individual chromophores $\mathrm{RhB}$ (3a) and PtTBP (1a) (Figure 2).

The efficiency of the FRET ( $\left.\phi_{\mathrm{FRET}}=0.84\right)$ and the phosphorescence quantum yield $\left(\phi_{\mathrm{p}}=\right.$ 0.052 ) of adduct 8 were greatly improved compared to those of 5 . Upon excitation at $520 \mathrm{~nm}$, where the absorbance of PtTBP itself is weak, phosphorescence from adduct 8 was more than 100 times stronger than that of $\mathbf{5}$ and 10 times stronger than that of the reference porphyrin 1a. However, the phosphorescence quantum yield of PtTBP in 8 appeared to be only $63 \%$ of that for $1 \mathrm{a}(0.052 \mathrm{vs} 0.083$ in EtOH, Table 1). According to our calculations, at the distance of $40 \AA$ the rate of quenching by $\mathrm{ET}_{\mathrm{PtTBP}(\mathrm{T})}$ should constitute only about $10 \%$ of the rate of PtTBP phosphorescence, and the quantum yield of the phosphorescence should be about 0.075 . As mentioned earlier, parameter $\beta$, used in our calculations, was most likely too high to be applied to $\mathrm{ET}_{\mathrm{PtTBP}(\mathrm{T})}$, and it is possible that the residual electron transfer was responsible for the decrease in the quantum yield. On the other hand, the phosphorescence quantum yield of 8 practically did not change upon changing the solvent (Table 1), whereas ET rates are typically very sensitive to the solvent dielectric constant. It is therefore also possible that lower phosphorescence quantum yield is an intrinsic property of PtTBP chromophore in $\mathbf{8}$. 
Emission spectra of $\mathbf{8}$ and $3 \mathbf{a}$ (Figure $6 \mathrm{~A}$ ) reveal that $84 \%$ of $\mathrm{RhB}$ fluorescence in $\mathbf{8}$ is quenched. On the other hand, comparison of the excitation and the absorption spectra of 8 (Figure 6B) shows that the same $84 \%$ of the excitation energy is being transferred to PtTBP. Thus, $\mathrm{ET}_{\mathrm{RhB}(\mathrm{S})}$ and $\mathrm{ET}_{\mathrm{PtTBP}(\mathrm{S})}$, involving short-lived singlet states, were entirely suppressed by inserting a decaproline spacer between RhB and PtTBP. At the same time, the FRET efficiency in 8 remained quite high $\left(\phi_{\mathrm{FRET}}=0.84\right)$. Amazingly, calculations based on the Förster theory predict that for the RhB-PtTBP pair the FRET efficiency at the distance of $40 \AA$ should be $\phi_{\text {FRET }}=0.84$ ! Although such an agreement is probably a coincidence, good correspondence of experimental rates to the Förster model is expected at larger separations between donor and acceptor sites.

The steady-state evaluation of the FRET efficiency was confirmed by fluorescence time resolved measurements. Fluorescence decays of compounds $\mathbf{8}$ and $\mathbf{3 a}$ and the corresponding lifetime distributions 63 are shown in Figure 7.

In the absence of quenching, 3a reveals practically a single-exponential decay, i.e., a narrow uniform distribution of lifetimes (Figure 7B), centered at around $\tau_{\mathrm{av}}=1.82 \mathrm{~ns} .{ }^{64}$ In the case of $\mathbf{8}$, the distribution moves to shorter lifetimes $\left(\tau_{\mathrm{av}}=0.33 \mathrm{~ns}\right)$ and broadens asymmetrically, which is expected for the FRET. ${ }^{65}$ The ensemble broadening reflects the distribution of distances between the donor and the acceptor in the dyad. A small second maximum around $1.8 \mathrm{~ns}$ is due to the contamination of $\mathbf{8}$ by unbound RhB. The ratio of the distribution averages for $\mathbf{8}$ and 3a corresponds to the FRET efficiency of 0.82 , which is very close to the value calculated from the steady-state measurements (0.84).

Our last model compound, $\mathbf{9}$, was designed to evaluate how the increase in the number of the antenna chromophores would influence the overall performance of the 2PA phosphorescent sensors. The phosphorescence quantum yield of 9 was 0.028 , which again can be explained by the residual quenching via $\mathrm{ET}_{\mathrm{PtTBP}(\mathrm{T})}$ and taking into account that the number of quenching chromophores (RhB) in 9 is 4 times that in $\mathbf{8}$. RhB fluorescence in 9 was quenched by $84 \%$, and the fluorescence lifetime measurements were in good agreement with the spectroscopic data. However, only 55\% of the absorbed energy, according to the absorption/excitation spectra, was transferred to the PtTBP. Because distances between the RhB and PtTBP moieties in 9 are the same as in $\mathbf{1}$, and $\mathrm{ET}_{\mathrm{RhB}(\mathrm{S})}$ in $\mathbf{8}$ was shown to be negligible, quenching of $\mathrm{RhB}$ fluorescence by intramolecular electron transfer was ruled out. It is possible that a part of the quenching arises from the formation of nonemitting $\mathrm{RhB}$ aggregates within the molecule of 9. Although $\mathrm{Pro}_{10}$ rods are rigid, their linkages to PtTBP meso-aryl rings are quite flexible, and $\mathrm{RhB}$ termini in 9 can easily experience close contacts with each other in solution. Selfquenching in rhodamine aggregates is a well-documented phenomenon. 66

\section{Two-Photon-Excitation Experiments}

Two-photon-excitation experiments were designed to (1) estimate 2PA cross sections of core PtTBPs and (2) quantify enhancement of the 2PA-induced phosphorescence via energy transfer from the antenna rhodamines. 2PA cross sections $\left(\sigma_{2}\right)$ were measured by the relative emission method. To quantify enhancement of the signal in antenna-emitter systems, we used the apparent gain parameter $\gamma,{ }^{26}$ which relates emission from the molecular device $\mathrm{D}\left(I^{\mathrm{D}}\right)$ to that of the "naked" core $\mathrm{C}\left(I^{\mathrm{C}}\right)$ :

$$
\gamma=I^{\mathrm{D}} / I^{\mathrm{C}}
$$

In addition, parameter $\gamma_{\mathrm{e}}$ was used to characterize the expected gain:67

$$
\gamma_{\mathrm{e}}=\frac{\left(\sigma_{2}{ }^{\mathrm{A}} \varphi_{\text {FRET }}{ }^{\mathrm{D}}+\sigma_{2}{ }^{\mathrm{C}}\right) \varphi_{\mathrm{p}}{ }^{\mathrm{D}}}{\sigma_{2}{ }^{\mathrm{C}} \varphi_{\mathrm{p}}{ }^{\mathrm{C}}}
$$


where $\sigma_{2}{ }^{\mathrm{A}}$ and $\sigma_{2}{ }^{\mathrm{C}}$ are the 2PA cross sections of the antenna and the core, respectively, the quantum yields of the phosphorescence $\left(\phi_{\mathrm{p}}\right)$ and the FRET ( $\left.\phi_{\mathrm{FRET}}\right)$ are determined from independent linear measurements, and superscripts " $A$ ", " $C$ ", and " $D$ " refer to the antenna, the core, and the whole device, respectively. Formula 3 is useful because it allows estimation of the 2PA cross section of the device, provided that the FRET and the phosphorescence are independent of the excitation type (1P vs $2 \mathrm{P})$.

As mentioned in the Introduction, in all 2PA antenna/core systems described so far, 26,27 experimental gain coefficients $\gamma$ were significantly lower than the theoretically expected $\left(\gamma_{\mathrm{e}}\right)$, especially in the systems designed for singlet oxygen sensitization. ${ }^{27}$ In these molecules, powerful 2PA antenna dyes (hundreds to thousands of GM units) have been utilized, and the apparent fluorescence quantum yields were high. Nevertheless, gain factors appeared to be tens-to-hundreds of times lower than expected form 2PA cross sections of the antenna.

A. Core Porphyrins-Evaluation of 2PA cross sections of phosphorescent PtTBPs was necessary for quantification of the enhancement effect. Tetraaryltetrabenzoporphyrins possess highly nonplanar molecular structures. Saddling of the porphyrin macrocycle leads to the loss of the center of symmetry and, as a result, should affect its $2 \mathrm{PA}$ cross section. In addition, $\pi$ extension of the porphyrin macrocycle might have its own influence on the 2PA.

To estimate 2PA cross sections of tetraaryltetrabenzoporphyrins, we used fluorescent nonplanar free-base tetraphenyltetrabenzoporphyrin $10,46 \mathrm{~b}$ instead of phosphorescent $\mathrm{Pt}$ complexes $\mathbf{1}$ and $\mathbf{2}$, and tetracarboxyphenylporphyrin $\mathbf{1 1}^{68}$ as a reference planar porphyrin (Figure 8).

Measurement by the relative emission method is based on the comparison between emissions from the sample of interest and a standard with the known 2PA cross section. It is necessary that measurements are performed significantly below the saturation limit, where power dependence of the signal follows the quadratic law. In the case of phosphorescent samples, signal saturation upon excitation by high repetition rate lasers occurs already at quite low powers due to long triplet-state lifetimes (tens of microseconds), whereas measurements at lower powers are inaccurate because of low signal-to-noise ratios. (An indication of the saturation effect has been observed in our experiments.) In addition, triplet states of porphyrins can also be capable of multiphoton absorption, and transitions like $\mathrm{T}_{1} \rightarrow \mathrm{T}_{2}$ via $2 \mathrm{PA}$ can additionally distort measurements of the ground-state $2 \mathrm{PA}$ cross sections. Using low repetition rate (e.g., $1 \mathrm{kHz}$ ) regenerative amplifiers would help solving these problems, although high per-pulse powers would be required to obtain adequate signals. On the other hand, standard high repetition rate Ti:sapphire oscillators are entirely suitable for measuring fluorescent chromophores with lifetimes below, e.g., $5 \mathrm{~ns}$. Therefore, using fluorescent porphyrin $\mathbf{1 0}$ instead of 2 was a convenient way to evaluate the 2PA cross section of the tetraaryltetrabenzoporphyrin macrocycle.

Although porphyrins $\mathbf{1 0}$ and $\mathbf{1 1}$ are reasonably well soluble in aqueous solutions at basic $\mathrm{pH}$, to avoid aggregation they were bound to bovine serum albumin (BSA, 1\% aqueous solution). BSA is known to form complexes with porphyrins and has been used as a porphyrin carrier for construction of oxygen-sensitive probes. 16 Our laser system ( $76 \mathrm{MHz}$ repetition rate) was tuned to $840 \mathrm{~nm}$. The emission spectra of $\mathbf{1 0}$ and $\mathbf{1 1}$, normalized by molar concentrations and extinctions at $\lambda_{\text {ex }}$, and their power dependence plots are shown in Figure 9. The plot of fluorescence of Rhodamine B, used as a standard, is also shown for comparison.

Power dependences for Rhodamine B and $\mathbf{1 1}$ exhibit almost pure second order. In the case of 10 linear absorption was still significant, indicating that for $2 \mathrm{P}$-imaging experiments the wavelength should be shifted further to the red. The values of $2 \mathrm{PA}$ cross sections for $\mathbf{1 0}$ and 
$\mathbf{1 1}$ were calculated as averages for all excitation powers, in the case of $\mathbf{1 0}$ after subtraction of the linear component. The calculations were based on the following data: for 10, $\epsilon(646 \mathrm{~nm})=$ $31000 \mathrm{M}^{-1} \mathrm{~cm}^{-1}, \phi_{\mathrm{fl}}=0.032 ;{ }^{69}$ for $11, \epsilon(517 \mathrm{~nm})=19000 \mathrm{M}^{-1} \mathrm{~cm}^{-1,70} \phi_{\mathrm{fl}}=0.15 ;{ }^{69}$ for Rhodamine B, $\epsilon(547 \mathrm{~nm})=107000 \mathrm{M}^{-1} \mathrm{~cm}^{-1,71} \phi_{\mathrm{fl}}=0.85,{ }^{40} \sigma_{2}(840 \mathrm{~nm})=200 \mathrm{GM} .{ }^{8 \mathrm{a}}$ The 2PA cross section of planar porphyrin 11 was found to be low (about $2 \mathrm{GM}$ ), consistent with its high symmetry and with earlier reported measurements. 21,26 The 2 PA cross section of tetrabenzoporphyrin $\mathbf{1 0}$ appeared to be more than 10 times higher than that of 11, supporting expectations regarding the effects of nonplanarity and, possibly, of $\pi$-extension. The $\sigma_{2}$ value of $28 \mathrm{GM}$ for porphyrin $\mathbf{1 0}$ is consistent with the earlier reported numbers, $21 \mathrm{~b}$ and gives a rough approximation for the 2PA cross sections of PtTBPs 1 and 2.

Attempts to directly measure 2PA cross sections of PtTBPs led us to an interesting and relevant observation. To monitor phosphorescence of porphyrins $\mathbf{1 a}$ and $\mathbf{2 b}$ and dyads $\mathbf{8}$ and $\mathbf{9}$, we used a time-resolved-phosphorescence measurement system, which was coupled to a regenerative amplifier (30 fs, $1 \mathrm{kHz}$ ) operating at $\lambda_{\max }=820 \mathrm{~nm}$. Using the low repetition rate laser allowed collection of complete phosphorescence decays, making it possible to avoid the saturation effects and triplet-triplet excitation via $2 \mathrm{PA}$.

The power dependence plots for both cores $\mathbf{1 a}$ and $\mathbf{2 b}$ turned out to be practically linear (Figure $10 \mathrm{~A}$ ) in spite of the fact that the laser excitation was more than $200 \mathrm{~nm}$ away from the lowest energy linear absorption band $\left(\lambda_{\max }=611-615 \mathrm{~nm}\right)$. Detailed examination of the absorption spectrum of $\mathbf{2 b}$, taken at a very high concentration $\left(\sim 10^{-3} \mathrm{M}\right)$, revealed the presence of a band $\left(\lambda_{\max }=762 \mathrm{~nm}, \epsilon=120 \mathrm{M}^{-1} \mathrm{~cm}^{-1}\right)$ which was attributed to $\mathrm{S}_{0} \rightarrow \mathrm{T}_{1}$ absorption (Figure 10B). The presence of relatively strong spin-forbidden transitions in the spectra of $\mathrm{Pd}$ and $\mathrm{Pt}$ porphyrins is known from the literature. ${ }^{57 \mathrm{~b}}$ These are usually attributed to strong spin-orbit couplings induced by the heavy atoms. However, the extinction coefficient of $120 \mathrm{M}^{-1} \mathrm{~cm}^{-1}$ is the highest, to our knowledge, reported for direct singlet-triplet absorption. Since the spectrum of the femtosecond source is intrinsically broadened due to the high temporal compression, overlap of the laser with the $\mathrm{S}_{0} \rightarrow \mathrm{T}_{1}$ band results in the linear rather than $2 \mathrm{P}$ excitation of phosphorescence. From the point of view of $2 \mathrm{P}$ imaging this means that using PtTBPs would require laser sources operating above, e.g., $900 \mathrm{~nm}$, where intrinsic 2PA cross sections of PtTBPs may be lower than in the region near $800 \mathrm{~nm}$.

B. RhB-PtTBP Assemblies-The power dependences of the phosphorescence from $\mathbf{8}$ and $\mathbf{9}$ are shown in Figure 11A,B together with reference plots for porphyrins $\mathbf{1 a}$ and $\mathbf{2 b}$. In spite of the interference by the linear $S_{0} \rightarrow T_{1}$ absorption (Figure 10B), the plots for 8 and 9 reveal notable second-order contribution, especially at higher powers, which is evidently due to the 2PA by the RhB antennae. The corresponding plots of the reference porphyrins $\mathbf{1 a}$ and $\mathbf{2} \mathbf{b}$ are practically linear. Fitting the normalized data for $\mathbf{8}$ and $\mathbf{9}$ by second-order polynomials and subtracting the linear components rendered pure quadratic plots (Figure 11C), from which the enhancement ratio of $\mathbf{9}$ vs $\mathbf{8}$ could be calculated as the ratio of coefficients $b(9) / b(8)=2.95$. This value is even slightly higher than the theoretically predicted ratio of 2.4 , obtained by applying eq 3 to the pair $\mathbf{9}$ vs $\mathbf{8}$ and accounting for the difference in the quantum yields of these compounds. To use eq 3 , we considered that 9 has three more RhB $\left(\sigma_{2}=180 \mathrm{GM}\right)$ units than $\mathbf{8}$, and assumed that the 2PA cross section of the core PtTBP in both $\mathbf{8}$ and $\mathbf{9}$ is the same as for the model porphyrin 10, i.e., $28 \mathrm{GM}$. The corresponding coefficients $\gamma$ and $\gamma_{\mathrm{e}}$ (eqs 2 and 3) for 9 vs 8 were in excellent agreement, i.e., 1.25 and 1.28, respectively, indicating linear increase in the 2PA cross section with an increase in the number of RhB antenna units going from mono$\mathrm{RhB}$ to tetra-RhB adduct.

Estimation of the 2PA enhancement effect for compounds 9 and $\mathbf{8}$ relative to their parent core porphyrins $\mathbf{1 a}$ and $\mathbf{2 b}$ was complicated due to the linear $\mathrm{S}_{0} \rightarrow \mathrm{T}_{1}$ transition in the absorption spectrum of PtTBP. The apparent enhancement ratios for $\mathbf{8}$ vs $\mathbf{1 a}$ and $\mathbf{9}$ vs $\mathbf{2 b}$, normalized by 
the phosphorescence quantum yields, were 1.7 and 1.3 , respectively, which is substantially lower than the values calculated based on $2 \mathrm{PA}$ cross sections of the components, i.e., 6.4 and 15.1. To move the excitation away from $\mathrm{S}_{0} \rightarrow \mathrm{T}_{1}$ band, we performed measurements of compound $\mathbf{8}$ and of its reference porphyrin 1a using the source operating at $840 \mathrm{~nm}(110 \mathrm{fs}$, $76 \mathrm{MHz}$ ). The corresponding corrected emission spectra are shown in Figure 12.

The long wavelength edges of the phosphorescence peaks of both $\mathbf{8}$ and $\mathbf{1 a}$ are truncated as a result of the correction for the excitation leak. The laser radiation intensity at above $800 \mathrm{~nm}$ was still quite high and diminished the accuracy of the spectral registration. Nevertheless, the apparent gain coefficient $\gamma=4.2$, determined by this method for $\mathbf{8} \mathrm{vs} \mathbf{1 a}$, was found to be reasonably close to the predicted gain $\gamma_{\mathrm{e}}=3.7$. On the basis of this value of $\gamma$, the 2PA cross section of PtTBP in $\mathbf{8}$ was calculated to be $23.8 \mathrm{GM}$, which is very close to the value of $\sigma_{2}$ determined for free-base tetrabenzoporphyrin $\mathbf{1 0}$.

The ratios of PtTBP phosphorescence/RhB fluorescence were dramatically different whether $2 \mathrm{P}$ or $1 \mathrm{P}$ excitation was used. This decrease is likely to be a manifestation of the saturation effect or $2 \mathrm{P}$ triplet-triplet absorption in $\mathbf{8}$, upon irradiation by high repetition rate lasers; however, further studies will be required to elucidate the origin of this effect.

\section{Conclusions}

Our foregoing experiments demonstrate that enhancement of 2PA-driven triplet-state generation can be accomplished via energy transfer from an appropriately chosen $2 \mathrm{PA}$ antenna. However, the molecular architecture of multiphoton phosphorescent systems requires to be manipulated in order to avoid interfering processes, such as intramolecular electron transfer. Several key conclusions, relevant to the design of enhanced phosphorescent sensors and multiphoton singlet oxygen sensitizers, are summarized below.

First, in these systems quenching of excited states, especially long-lived triplet states, by the competing electron transfer is a persistent problem. While triplet electron transfer can be reliably observed and quantified in the case of phosphorescent sensors, quenching of "dark" triplet states in singlet oxygen sensitizers can be not as apparent, and also detrimental to the overall performance. Since most 2PA dyes are conjugated, polarizable molecules, electron transfer is intrinsic to their combination with long-lived photoexcited chromophores. Careful redox tuning of 2PA dyes and/or triplet-state cores should be performed in order to minimize the driving force for unwanted electron-transfer processes.

Second, by using rigid oligoproline spacers for separating RhB antennae from triplet PtTBP cores in RhB-PtTBP assemblies, we have demonstrated that distance tuning can be an effective general method for optimization of 2PA FRET-based triplet systems. A distance can be selected at which electron-transfer processes are suppressed, while long-range Förster energy transfer still occurs with high efficiency.

Third, the presence of "hidden" low-energy transitions in the spectra of triplet-state emitters, e.g., metalloporphyrins with increased $\pi$-conjugation, might present a problem for excitation by a pure multiphoton mechanism. Such transitions are intrinsic to the systems with enhanced singlet-triplet conversion pathways, e.g., by the heavy atom effect. For example, in the case of PtTBP, a strong spin-forbidden $\mathrm{S}_{0} \rightarrow \mathrm{T}_{1}$ transition could be observed in the close vicinity of the Ti:sapphire laser spectrum, preventing efficient excitation by the $2 \mathrm{PA}$ mechanism.

Finally, our measurements demonstrate that the loss of the center of symmetry due to nonplanar distortion of the porphyrin macrocycle and its $\pi$-extension lead to a significant increase in $2 \mathrm{PA}$ cross section. For example, the 2PA cross section of saddled tetraaryltetrabenzoporphyrins in the region of $800 \mathrm{~nm}$ was estimated to be about an order of magnitude higher than that of a 
planar tetraarylporphyrin. The possibility of using asymmetric phosphorescent porphyrins directly as 2PA oxygen sensors will be explored in the future.

It should be mentioned that phosphorescence of all PtTBP-based molecules studied in this work was found to be extremely oxygen sensitive in organic solutions. However, determination of the actual Stern-Volmer oxygen quenching constants for RhB-PtTBP assemblies will need to be accomplished after modifying these systems to solubilize them in aqueous environments, e.g., by attaching appropriate dendritic arms. ${ }^{26}$ It is not clear at this point whether RhB-PtTBP systems themselves will become the probes of choice for $2 \mathrm{P}$ oxygen microscopy, primarily because of the difficulties associated with hidden $\mathrm{S}_{0}-\mathrm{T}_{1}$ bands of PtTBP cores. Nevertheless, analysis of these systems appeared to be informative and useful for future construction of optimized 2PA-enhanced functional triplet core systems.

\section{Acknowledgment}

Support from Grants EB007279 (S.A.V.), HL081273 (S.A.V.), GM54616 (W.F.D.), and P41-RR001348 (R.M.H.) from the NIH is gratefully acknowledged. W.F.D. also acknowledges support of Nano/Bio Interface Center (NSF IGERT DGE02-21664). We thank Prof. David F. Wilson for many useful discussions.

\section{References and Notes}

(1). The quantity $\sigma_{2}$ is commonly referred to as the "two-photon-absorption cross section," although it is not an area (see, for example: www.drbio.cornell.edu/MPE/mpe.html). It is the proportionality coefficient between the photon absorption rate per molecule $(\beta)$ and the time-averaged square of the photon flux $\Phi: \beta=\sigma_{2}\left\langle\Phi^{2}\right\rangle$. $\sigma_{2}$ is measured in GM (Göppert-Mayer) units: $1 \mathrm{GM}=10^{-50} \mathrm{~cm}^{4}$ s photon $^{-1}$

(2). Denk W, Strickler JH, Webb WW. Science 1990;248:73-76. [PubMed: 2321027]

(3)(a). Svoboda K, Yasuda R. Neuron 2006;50:823-839. [PubMed: 16772166]For recent reviews, see (b) Rothstein EC, Nauman M, Chesnick S, Balaban RS. J. Microsc. (Oxford) 2006;222:58-64. [PubMed: 16734715] (c) Helmchen F, Denk W. Nat. Methods 2005;2:932-940. [PubMed: 16299478] (d) Helmchen F, Denk W. Curr. Opin. Neurobiol 2002;12:593-601. [PubMed: $12367641]$

(4). Göppert-Mayer M. Ann. Phys 1931;9:273.

(5). Parthenopoulos DA, Rentzepis PM. Science 1989;245:843-845. [PubMed: 17773360]

(6)(a). He GS, Bhawalkar JD, Zhao CF, Prasad PN. Appl. Phys. Lett 1995;67:2433-2435.Lin, TC.; Chung, SJ.; Kim, KS.; Wang, XP.; He, GS.; Swiatkiewicz, J.; Pudavar, HE.; Prasad, PN. Polymers for Photonics Applications II; Advances in Polymer Science 161. Springer; Berlin: 2003. p. 157-193.

(7)(a). Bhawalkar DD, Kumar ND, Zhao CF, Prasad PN. J. Clin. Med. Surg 1997;37:210-204. (b) König K. J. Microsc 2000;200:83-104. [PubMed: 11106949] and references therein

(8)(a). Xu C, Webb WW. J. Opt. Soc. Am. B 1996;13:481-491. (b) Albota MA, Xu C, Webb WW. Appl. Opt 1998;37:7352-7356. [PubMed: 18301569]

(9)(a). Mongin O, Porres L, Charlot M, Katan C, Blanchard-Desce M. Chem.-Eur. J 2007;13:14811498.Examples of 2PA chromophores based on $\pi$-conjugated donor-acceptor systems (b) Chung SJ, et al. J. Am. Chem. Soc 2006;128:14444-14445. [PubMed: 17090012] (c) Morales AR, Belfield KD, Hales JM, Van Stryland EW, Hagan DJ. Chem. Mater 2006;18:4972-4980. (d) Krishna TR, Parent M, Werts MHV, Moreaux L, Gmouh S, Charpak S, Caminade AM, Majoral JP, BlanchardDesce M. Angew. Chem., Int. Ed 2006;45:4645-4648. (e) Kato S, Matsumoto T, Shigeiwa M, Gorohmaru H, Maeda S, Ishi-i T, Mataka S. Chem.-Eur. J 2006;12:2303-2317. (f) Huang PH, Shen JY, Pu SC, Wen YS, Lin JT, Chou PT, Yeh MCP. J. Mater. Chem 2006;16:850-857. (g) Hayek A, Nicoud JF, Bolze F, Bourgogne C, Baldeck PL. Angew. Chem., Int. Ed 2006;45:64666469. (h) Zheng QD, He GS, Prasad PN. J. Mater. Chem 2005;15:579-587. (i) Chung SJ, Rumi M, Alain V, Barlow S, Perry JW, Marder SR. J Am. Chem. Soc 2005;127:10844-10845. [PubMed: 16076186] (j) Woo HY, Hong JW, Liu B, Mikhailovsky A, Korystov D, Bazan GC. J. Am. Chem. Soc 2005;127:820-821. [PubMed: 15656604] (k) Oliveira SL, Correa DS, Misoguti L, Constantino CJL, Aroca RF, Zilio SC, Mendonca CR. Adv. Mater 2005;17:1890. 
(10)(a). Karotki A, Drobizhev M, Dzenis Y, Taylor PN, Anderson HL, Rebane A. Phys. Chem. Chem. Phys 2004;6:7-10.Examples of 2PA chromophores based on porphyrin conjugates and arrays (b) Drobizhev M, Stepanenko Y, Dzenis Y, Karotki A, Rebane A, Taylor PN, Anderson HL. J. Am. Chem. Soc 2004;126:15352-15353. [PubMed: 15563141] (c) Ogawa K, Ohashi A, Kobuke Y, Kamada K, Ohta K. J. Phys. Chem. B 2005;109:22003-22012. [PubMed: 16853858] (d) Drobizhev M, Stepanenko Y, Rebane A, Wilson CJ, Screen TEO, Anderson HL. J. Am. Chem. Soc 2006;128:12432-12433. [PubMed: 16984190] (e) Ahn TK, Kim KS, Kim DY, Noh SB, Aratani N, Ikeda C, Osuka A, Kim D. J. Am. Chem. Soc 2006;128:1700-1704. [PubMed: 16448144]

(11)(a). Ahn TK, Kwon JH, Kim DY, Cho DW, Jeong DH, Kim SK, Suzuki M, Shimizu S, Osuka A, Kim D. J. Am. Chem. Soc 2005;127:12856-12861. [PubMed: 16159279]Examples of 2PA chromophores based on modified porphyrins (b) Kwon JH, Ahn TK, Yoon MC, Kim DY, Koh MK, Kim D, Furuta H, Suzuki M, Osuka A. J. Phys. Chem. B 2006;110:11683-11690. [PubMed: 16800463] (c) Rath H, Prabhuraja V, Chandrashekar TK, Nag A, Goswami D, Joshi BS. Org. Lett 2006;8:2325-2328. [PubMed: 16706517] (d) Kurotobi K, Kim KS, Noh SB, Kim D, Osuka A. Angew. Chem., Int. Ed 2006;45:3944-3947. (e) Kim DY, Alm TK, Kwon JH, Kim D, Ikeue T, Aratani N, Osuka A, Shigeiwa M, Maeda S. J. Phys. Chem. A 2005;109:2996-2999. [PubMed: 16833622] (f) Inokuma Y, Ono N, Uno H, Kim DY, Noh SB, Kim D, Osuka A. Chem. Commun 2005:3782-3784.

(12)(a). Adronov A, Fréchet JMJ, He GS, Kim KS, Chung SJ, Swiatkiewicz J, Prasad PN. Chem. Mater 2000;12:2838.Examples of 2PA chromophores based on dendrimers (b) Drobizhev M, Karotki A, Rebane A, Spangler CW. Opt. Lett 2001;26:1081-1083. [PubMed: 18049526] (c) Drobizhev M, Karotki A, Dzenis Y, Rebane A, Suo ZY, Spangler CW. J. Phys. Chem. B 2003;107:7540-7543. (d) Brousmiche DW, Serin JM, Fréchet JMJ, He GS, Lin TC, Chung SJ, Prasad PN, Kannan R, Tan LS. J. Phys. Chem. B 2004;108:8592-8600. (e) Wei P, Bi XD, Wu Z, Xu Z. Org. Lett 2005;7:3199_ 3202. [PubMed: 16018620] (f) Mongin O, Krishna TR, Werts MHV, Caminade AM, Majoral JP, Blanchard-Desce M. Chem. Commun 2006:915-917. (g) Bhaskar A, Guda R, Haley MM, Goodson T. J. Am. Chem. Soc 2006;128:13972-13973. [PubMed: 17061848]

(13)(a). Collini E, Ferrante C, Bozio R. J. Phys. Chem. B 2005;109:2-5. [PubMed: 16850971]2PA porphyrin aggregates (b) Ray PC, Sainudeen Z. J. Phys. Chem. A 2006;110:12342-12347. [PubMed: 17078634]

(14). Larson DR, Zipfel WR, Williams RM, Clark SW, Bruchez MP, Wise FW, Webb WW. Science 2003;300:1434-1436. [PubMed: 12775841]Quantum dots

(15)(a). Albota M, Beljonne D, Bredas JL, Ehrlich JE, Fu JY, Heikal AA, Hess SE, Kogej T, Levin MD, Marder SR, McCord-Maughon D, Perry JW, Rockel H, Rumi M, Subramaniam C, Webb WW, Wu XL, Xu C. Science 1998;281:1653-1656. [PubMed: 9733507] (b) Rumi M, Ehrlich JE, Heikal AA, Perry JW, Barlow S, Hu ZY, McCord-Maughon D, Parker TC, Rockel H, Thayumanavan S, Marder SR, Beljonne D, Bredas JL. J. Am. Chem. Soc 2000;122:9500-9510.

(16)(a). Vanderkooi JM, Maniara G, Green TJ, Wilson DF. J. Biol. Chem 1987;262:5476-5483. [PubMed: 3571219]Wilson, DF.; Vinogradov, SA. Handbook of Biomedical Fluorescence. Mycek, M-A.; Pogue, BW., editors. Marcel Dekker, Inc.; New York: 2003. Chapter 17

(17). Demas JN, DeGraff BA, Coleman PB. Anal. Chem 1999;71:793A-800A.We limit our scope by the literature on oxygen measurements using molecular probes introduced directly into the medium of interest, e.g., blood or interstitial space. In addition, there is a large area of research covering solidstate phosphorescent oxygen sensors. For a review, see

(18)(a). Pittman RN. Microcirculation 2005;12:59-70. [PubMed: 15804974]For the latest examples, see (b) Ferreira LF, McDonough P, Behnke BJ, Musch TI, Poole DC. Resp. Physiol. Neurobiol 2006;153:237-249. (c) Johannes T, Mik EG, Ince C. J. Appl. Physiol 2006;100:1301-1310. [PubMed: 16357065] (d) Tsai AG, Friesenecker B, Cabrales P, Hangai-Hoger N, Intaglietta M. Curr. Opin. Nephrol. Hypertens 2006;15:67-71. [PubMed: 16340669] (e) Wilson DF, Lee WMF, Makonnen S, Finikova O, Apreleva S, Vinogradov SA. J. Appl. Physiol 2006;101:1648-1656. [PubMed: 16888050] (f) Zaitseva T, Schultz S, Schears G, Pastuszko P, Markowitz S, Greeley W, Wilson DF, Pastuszko A. Ann. Thoracic Surg 2006;82:2247-2253.

(19)(a). Rumsey WL, Vanderkooi JM, Wilson DF. Science 1988;241:1649-1652. [PubMed: 3420417] For examples, see (b) Plant RL, Burns DH. Appl. Spectrosc 1993;47:1594-1599. (c) Vinogradov SA, Lo L-W, Jenkins WT, Evans SM, Koch C, Wilson DF. Biophys. J 1996;70:1609-1617. [PubMed: 8785320] (d) Smith LM, Golub AS, Pittman RN. Microcirculation 2002;9:389-395. 
[PubMed: 12375176] (e) Golub AS, Pittman RN. FASEB J 2002;16:A520-A520. (f) Shonat RD, Kight AC. Ann. Biomed. Eng 2003;31:1084-1096. [PubMed: 14582611] (g) Apreleva SV, Wilson DF, Vinogradov SA. Appl. Opt 2006;45:8547-8559. [PubMed: 17086268] (h) Shahidi M, Shakoor A, Blair NP, Mori M, Shonat RD. Curr. Eye Res 2006;31:357-366. [PubMed: 16603469]

(20)(a). Eastwood D, Gouterman M. J. Mol. Spectrosc 1970;35:359-375. (b) Callis JB, Knowles JM, Gouterman M. J. Phys. Chem 1973;77:154-156. [PubMed: 4683215] (c) Kim DH, Holten D, Gouterman M, Buchler JW. J. Am. Chem. Soc 1984;106:4015-4017. (d) Vinogradov SA, Wilson DF. J. Chem. Soc., Perkin Trans. 2 1995:103-111.

(21)(a). Kruk M, Karotki A, Drobizhev M, Kuzmitsky V, Gael V, Rebane A. J. Lumin 2003;105:45-55. (b) Karotki A, Drobizhev M, Kruk M, Spangler C, Nickel E, Mamardashvili N, Rebane A. J. Opt. Soc. Am. B 2003;20:321.5. (c) Karotki A, Khurana M, Lepock JR, Wilson BC. Photochem. Photobiol 2006;82:443-452. [PubMed: 16613497]

(22)(a). Castellano FN, Malak H, Gryczynski I, Lakowicz JR. Inorg. Chem 1997;36:5548-5551. (b) Lakowicz JR, Castellano FN, Gryczynski I, Gryczynski Z, Dattelbaum JD. J. Photochem. Photobiol. Chem 1999;122:95-101.

(23). Mik EG, van Leeuwen TG, Raat NJ, Ince C. J. Appl. Physiol 2004;97:1962-1969. [PubMed: 15247164]Although 2P excitation of metalloporphyrins has been reported to induce their phosphorescencefor biological imaging applications 2PA cross sections of phosphorescent probes must be significantly higher

(24)(a). Karotki A, Drobizhev M, Kruk M, Spangler C, Nickel E, Mamardashvili N, Rebane A. J. Opt. Soc. Am. B 2003;20:321-332. (b) Drobizhev M, Karotki A, Kruk M, Mamardashvili NZ, Rebane A. Chem. Phys. Lett 2002;361:504-512. (c) Drobizhev M, Karotki A, Kruk M, Rebane A. Chem. Phys. Lett 2002;355:175-182. (d) Drobizhev M, Meng FQ, Rebane A, Stepanenko Y, Nickel E, Spangler CW. J. Phys. Chem. B 2006;110:9802-9814. [PubMed: 16706432] (e) Morone M, Beverina L, Abbotto A, Silvestri F, Collini E, Ferrante C, Bozio R, Pagani GA. Org. Lett 2006;8:2719-2722. [PubMed: 16774240]

(25). Duncan TV, Susumu K, Sinks LE, Therien MJ. J. Am. Chem. Soc 2006;128:9000-9001. [PubMed: 16834350]

(26). Briñas RP, Troxler T, Hochstrasser RM, Vinogradov SA. J. Am. Chem. Soc 2005;127:1185111862. [PubMed: 16104764]

(27)(a). Dichtel WR, Serin JM, Edder C, Fréchet JMJ, Matuszewski M, Tan LS, Ohulchanskyy TY, Prasad PN. J. Am. Chem. Soc 2004;126:5380-5381. [PubMed: 15113208] (b) Oar MA, Serin JM, Dichtel WR, Fréchet JMJ. Chem. Mater 2005;17:2267-2275.

(28). Wecksler SR, Mikhailovsky A, Korystov D, Ford PC. J. Am. Chem. Soc 2006;128:3831-3837. [PubMed: 16536559]A similar idea has recently been utilized to photochemically release nitric oxide upon $2 \mathrm{P}$ excitation

(29)(a). Vinogradov SA, Lo LW, Wilson DF. Chem.-Eur. J 1999;5:1338-1347. (b) Rozhkov V, Wilson D, Vinogradov S. Macromolecules 2002;35:1991-1993. (c) Rietveld IB, Kim E, Vinogradov SA. Tetrahedron 2003;59:3821-3831.

(30). Förster, T. Fluorenzenz Organische Verbindungen. Vandenhoech and Ruprech: Gottingen; 1951.

(31). Turro, NJ. Modern Molecular Photochemistry. University Science Books; Sausalito, CA: 1991.

(32). Marcus RA, Sutin N. Biochim. Biophys. Acta 1985;811:265.

(33)(a). Isied SS, Ogawa MY, Wishart JF. Chem. Rev 1992;92:381-394.For reviews, seeBalzani, V., editor. Electron Transfer in Chemistry. Wiley-VCH: Weinheim; 2001.

(34). Moser CC, Page CC, Cogdell RJ, Barber J, Wraight CA, Dutton PL. Adv. Protein Chem. Membr. Proteins 2003;63:71-109.

(35)(a). Mattay, J., editor. Photoinduced Electron Transfer. Springer-Verlag; New York: 1990. For books and reviews, see (b) Wasielewski MR. Chem. Rev 1992;92:435-461. (c) Winkler JR, Gray HB. Chem. Rev 1992;92:369-379.Gust, D.; Moore, TA. The Porphyrin Handbook. Kadish, KM.; Smith, KM.; Guilard, R., editors. 8. Academic Press; New York: 2000. Chapter 57 (e) Balzani V, Juris A. Coord. Chem. Rev 2001;211:97-115. (f) Nantalaksakul A, Reddy DR, Bardeen CJ, Thayumanavan S. Photosynth. Res 2006;87:133-150. [PubMed: 16408144]

(36)(a). Xiao SQ, El-Khouly ME, Li YL, Gan ZH, Liu HB, Jiang L, Araki Y, Ito O, Zhu D. J. Phys. Chem. B 2005;109:3658-3667. [PubMed: 16851404]For recent reports, see (b) Yan XZ, Goodson 
T, Imaoka T, Yamamoto K. J. Phys. Chem. B 2005;109:9321-9329. [PubMed: 16852116] (c) Ahn TS, Nantalaksakul A, Dasari RR, Al-Kaysi RO, Muller AM, Thayumanavan S, Bardeen CJ. J. Phys. Chem. B 2006;110:24331-24339. [PubMed: 17134184] (d) Cho S, Li WS, Yoon MC, Ahn TK, Jiang DL, Kim J, Aida T, Kim D. Chem.-Eur. J 2006;12:7576-7584. (e) Flamigni L, Talarico AM, Ventura B, Sooambar C, Solladie N. Eur. J. Inorg. Chem 2006:2155-2165. (f) Ito F, Ishibashi Y, Khan SR, Miyasaka H, Kameyama K, Morisue M, Satake A, Ogawa K, Kobuke Y. J. Phys. Chem. A 2006;110:12734-12742. [PubMed: 17125286] (g) Kodis G, Terazono Y, Liddell PA, Andreasson J, Garg V, Hambourger M, Moore TA, Moore AL, Gust D. J. Am. Chem. Soc 2006;128:1818-1827. [PubMed: 16464080] (h) Pettersson K, Kyrychenko A, Ronnow E, Ljungdahl T, Martensson J, Albinsson B. J. Phys. Chem. A 2006;110:310-318. [PubMed: 16392870] (i) Ermilov EA, Tannert S, Werncke T, Choi MTM, Ng DKP, Röder B. Chem. Phys 2006;328:428-437.

(37)(a). Joshi MP, Swiatkiewicz J, Xu FM, Prasad PN. Opt. Lett 1998;23:1742-1744. [PubMed: 18091900] (b) Chung SJ, Lin TC, Kim KS, He GS, Swiatkiewicz J, Prasad PN, Baker GA, Bright FV. Chem. Mater 2001;13:4071-4076. (c) Chiang LY, Padmawar PA, Canteenwala T, Tan LS, He GS, Kannan R, Vaia R, Lin TC, Zheng QD, Prasad PN. Chem. Commun 2002:1854-1855. (d) Brousmiche DW, Serin JM, Fréchet JMJ, He GS, Lin TC, Chung SJ, Prasad PN. J. Am. Chem. Soc 2003;125:1448-1449. [PubMed: 12568583] (e) He GS, Lin TC, Cui YP, Prasad PN, Brousmiche DW, Serin JM, Fréchet JMJ. Opt. Lett 2003;28:768-770. [PubMed: 12779140] (f) Brousmiche DW, Serin JM, Fréchet JMJ, He GS, Lin TC, Chung SJ, Prasad PN, Kannan R, Tan LS. J. Phys. Chem. B 2004;108:8592-8600.

(38)(a). Andrews DL, Bradshaw DS. J. Chem. Phys 2004;121:2445-2454. [PubMed: 15260800]For a theoretical treatment, see (b) Bradshaw DS, Andrews DL. Chem. Phys. Lett 2006;430:191-194.

(39). Kauert M, Stoller PC, Frenz M, Ricka J. Opt. Express 2006;14:8434-8447.In a recent studythe 2PA cross section of Rhodamine $\mathrm{B}$ in $\mathrm{MeOH}$ was rigorously measured and shown to have the value $\sigma_{2}$ $=24.4 \mathrm{GM}$ at $800 \mathrm{~nm}$, which is about 6 times lower than that reported by Xu and Webb $\left(\sigma_{2}=150\right.$ GM). ${ }^{8 \mathrm{a}}$ Nevertheless, we chose to use the commonly referred to value from ref $8 \mathrm{a}$ in order to facilitate comparison with the current literature

(40). Demas JN, Crosby GA. J. Phys. Chem 1971;75:991-1024.Several values have been reported in the literature for the fluorescence quantum yield of Rhodamine B, ranging from 0.41 to $0.97 \mathrm{We}$ used the value of 0.5 , reported by Karstens and Kobs 41 and rigorously confirmed by our own measurements

(41). Karstens T, Kobs K. J. Phys. Chem 1980;84:1871-1872.

(42). Nguyen T, Francis MB. Org. Lett 2003;5:3245-3248. [PubMed: 12943398]

(43)(a). Tsvirko MP, Sapunov VV, Soloviyev KN. Opt. Spektrosk. (Russ.) 1973;34:1094-1100. (b) Aartsma TJ, Gouterman M, Jochum C, Kwiram AL, Pepich BV, Williams LD. J. Am. Chem. Soc 1982;104:6278-6283. (c) Rogers JE, Nguyen KA, Hufnagle DC, McLean DG, Su WJ, Gossett KM, Burke AR, Vinogradov SA, Pachter R, Fleitz PA. J. Phys. Chem. A 2003;107:11331-11339. (d) Finikova OS, Cheprakov AV, Vinogradov SA. J. Org. Chem 2005;70:9562-9572. [PubMed: 16268634]

(44)(a). Finikova O, Cheprakov A, Beletskaya I, Vinogradov S. Chem. Commun 2001:261-262. (b) Finikova OS, Cheprakov AV, Beletskaya IP, Carroll PJ, Vinogradov SA. J. Org. Chem 2004;69:522-535. [PubMed: 14725469]

(45). For calculations of the Förster distance $r_{0}$, energy-transfer rates, and electron-transfer rates, see the Supporting Information

(46)(a). Cheng RJ, Chen YR, Wang SL, Cheng CY. Polyhedron 1993;12:1353-1360. (b) Finikova OS, Cheprakov AV, Carroll PJ, Dalosto S, Vinogradov SA. Inorg. Chem 2002;41:6944-6946. [PubMed: 12495329]

(47)(a). Charlesworth P, Truscott TG, Kessel D, Medforth CJ, Smith KM. J. Chem. Soc., Faraday Trans 1994;90:1073-1076.For examples, see (b) Gentemann S, Medforth CJ, Forsyth TP, Nurco DJ, Smith KM, Fajer J, Holten D. J. Am. Chem. Soc 1994;116:7363. (c) Gentemann S, Medforth CJ, Ema T, Nelson NY, Smith KM, Fajer J, Holten D. Chem. Phys. Lett 1995;245:441-447. (d) Sazanovich IV, Galievsky VA, van Hoek A, Schaafsma TJ, Malinovskii VL, Holten D, Chirvony VS. J. Phys. Chem. B 2001;105:7818.

(48). Seybold PG, Gouterman M. J. Mol. Spectrosc 1969;31:1. 
(49). Weber G, Teale FWJ. Trans. Faraday Soc 1957;53:646-655.If measured against Rhodamine B in methanol $\left(\phi_{\mathrm{f} 1}=0.5\right),{ }^{40} \mathrm{H}_{2}$-TPP in deoxygenated benzene exhibits the absolute fluorescence quantum yield $\phi_{\mathrm{fl}}=0.048$. A much higher value for $\mathrm{H}_{2} \mathrm{TPP}\left(\phi_{\mathrm{fl}}=0.11\right)$ was reported by Seybold and Gouterman 48 and became a standard reference in porphyrin spectroscopy. The yield of $\phi_{\mathrm{fl}}=$ 0.11 was measured ${ }^{48}$ relative to the fluorescence of chlorophyll $b$ in benzene $\left(\phi_{\mathrm{fl}}=0.12\right)$, as reported by Weber and TealeIn the same paper, Weber and Teale report the quantum yield $\phi_{\mathrm{fl}}=0.97$ for Rhodamine B in EtOH. As shown later, ${ }^{41}$ this value is significantly overestimated

(50)(a). Sun XD, Li DM, Chen GD, Zhang JL. Dyes Pigm 2006;71:118-122. (b) Lagerberg JWM, Vanderwal J, Charlesworth P, Truscott TG, VanDerZee J, Schneckenburger H, Dubbelman T. Free Radical Biol. Med 1996;21:181-188. [PubMed: 8818633]

(51). Vuorimaa E, Lemmetyinen H, VanderAuweraer M, DeSchryver FC. Thin Solid Films 1995;268:114-120.

(52). The separation between the centers of mass of RhB and PtTBP in 5 was estimated as an average over 15 conformations, obtained by means of molecular dynamics, followed by geometry optimization for each conformation (MM+ force field) (see Supporting Information for details)

(53). Mugnier J, Pouget J, Bourson J, Valeur B. J. Lumin 1985;33:273-300.

(54). Rehm D, Weller A. Isr. J. Chem 1970;8:259.

(55). Fischer AB, Bronstein-Bonte I. J. Photochem 1985;30:475-485.

(56). The work term was calculated as in ref ${ }^{54}$, using the value of 36.7 for the dielectric permeativity of DMF and the distance of $7.5 \AA$ for the separation between PtTBP and RhB in RhB-PtTBP dyads

(57)(a). Chen PL, Tomov IV, Dvornikov AS, Nakashima M, Roach JF, Alabran DM, Rentzepis PM. J. Phys. Chem 1996;100:17507-17512. (b) Knyukshto VN, Shul'ga AM, Sagun EI, Zen'kevich EI. Opt. Spectrosc 2006;100:590-601.

(58)(a). Verhoeven JW. J. Photochem. Photobiol. C: Photochem. Rev 2006;7:40-60.For examples, see (b) Weiss EA, Ratner MA, Wasielewski MR. J. Phys. Chem. A 2003;107:3639-3647. (c) Hviid L, Bouwman WG, Paddon-Row MN, van Ramesdonk HJ, Verhoeven JW, Brouwer AM. Photochem. Photobiol. Sci 2003;2:995-1001. [PubMed: 14606754] (d) Kobori Y, Yamauchi S, Akiyama K, Tero-Kubota S, Imahori H, Fukuzumi S, Norris JR. Proc. Natl. Acad. Sci. U.S.A 2005;102:1001710022. [PubMed: 16014413]

(59). The value $\Delta r=3.4 \AA$ was calculated as the difference between the average end-to-end distances for the linkers consisting of piperazine (for adduct 5) and piperazine-glycine (for adduct $\mathbf{6}$ ). The distances were averaged over 15 conformations for each linker type (see Supporting Information for details)

(60). Schuler B, Lipman EA, Steinbach PJ, Kumke M, Eaton WA. Proc. Natl. Acad. Sci. U.S.A 2005;102:2754-2759. [PubMed: 15699337]

(61)(a). Axup AW, Albin M, Mayo SL, Crutchley RJ, Gray HB. J. Am. Chem. Soc 1988;110:435-439. (b) Cowan JA, Upmacis RK, Beratan DN, Onuchic JN, Gray HB. Ann. N.Y. Acad. Sci 1988;550:6884. [PubMed: 3245652] (c) Elias H, Chou MH, Winkler JR. J. Am. Chem. Soc 1988;110:429-434. (d) Karas JL, Lieber CM, Gray HB. J. Am. Chem. Soc 1988;110:599-600. (e) Meade TJ, Gray HB, Winkler JR. J. Am. Chem. Soc 1989;111:4353-4356. (f) Therien MJ, Selman M, Gray HB, Chang IJ, Winkler JR. J. Am. Chem. Soc 1990;112:2420-2422.

(62)(a). Steinberg IZ, Harrington WF, Berger A, Sela M, Katchalski E. J. Am. Chem. Soc 1960;82:52635279. (b) Engel J. Biopolymers 1966;4:945. (c) Schimmel PR, Flory PJ. Proc. Natl. Acad. Sci. U.S.A 1967;58:52. [PubMed: 5231619] (d) Stryer L, Haugland RP. Proc. Natl. Acad. Sci. U.S.A 1967;58:719. [PubMed: 5233469] (e) Deber CM, Bovey FA, Carver JP, Blout ER. J. Am. Chem. Soc 1970;92:6191. [PubMed: 5505620] (f) Torchia DA, Bovey FA. Macromolecules 1971;4:146. (g) Vassilian A; Wishart JF, van Hemelryck B, Schwarz H, Isied SS. J. Am. Chem. Soc 1990;112:7278-7286.

(63). Livesey AK, Brochon JC. Biophys. J 1987;52:693-706.Distributions were recovered by the MEMVinogradov SA, Wilson DF. Applied Spectrosc 2000;54:849-855.implemented as a recursive algorithm

(64). The width of a distribution recovered by a regularized inversion method, e.g., the maximum entropy method (MEM), symbolizes the uncertainty in the parameters evaluation and, therefore, is partially related to the noise in the data. 63 
(65). Wagner BD, Ware WR. J. Phys. Chem 1990;94:3489-3494.

(66)(a). Chibisov AK, Slavnova TD. J. Photochem 1978;8:285-297.For examples, see (b) Arbeloa IL, Ojeda PR. Chem. Phys. Lett 1982;87:556-560. (c) Hoekstra D, de Boer T, Klappe K, Wilschut J. Biochemistry 1984;23:5675-5681. [PubMed: 6098295] (d) Arbeloa FL, Ojeda PR, Arbeloa IL. J. Chem. Soc., Faraday Trans. 2 1988;84:1903-1912.

(67). A less general formula was used in our previous paper (ref 26), in which we assumed that the 2PA of the "naked" core was negligible compared to that of the antenna. When PtTBPs are being used as cores, eq 3 should be used instead

(68). Datta-Gupta N, Bardos TJ. J. Heterocycl. Chem 1966;3:495-502.

(69). Measured in this work

(70). Barnett GH, Hudson MF, Smith KM. J. Chem. Soc., Perkin Trans. 1 1975:1401-1403.

(71). Meallier P, Moullet M, Guittonneau S, Chabaud F, Chevrou P, Niemann C. Dyes Pigm 1998;36:161167. 


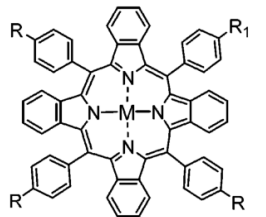

$1\left(\mathrm{M}=\mathrm{Pt}, \mathrm{R}=\mathrm{H}, \mathrm{R}_{1}=\mathrm{CO}_{2} \mathrm{H}\right)$

1a $\left(\mathrm{M}=\mathrm{Pt}, \mathrm{R}=\mathrm{H}, \mathrm{R}_{1}=\mathrm{CO}_{2} \mathrm{Me}\right)$

$2\left(\mathrm{M}=\mathrm{Pt}, \mathrm{R}=\mathrm{R}_{1}=\mathrm{CO}_{2} \mathrm{H}\right)$

2a $\left(M=\mathrm{H}_{2}, \mathrm{R}=\mathrm{R}_{1}=\mathrm{CO}_{2} \mathrm{Me}\right)$

$2 b\left(M=P t, R=R_{1}=\mathrm{CO}_{2} \mathrm{Me}\right)$

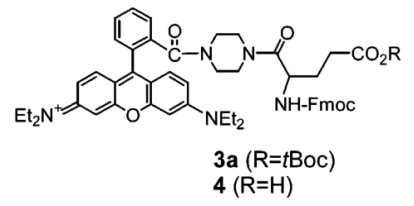

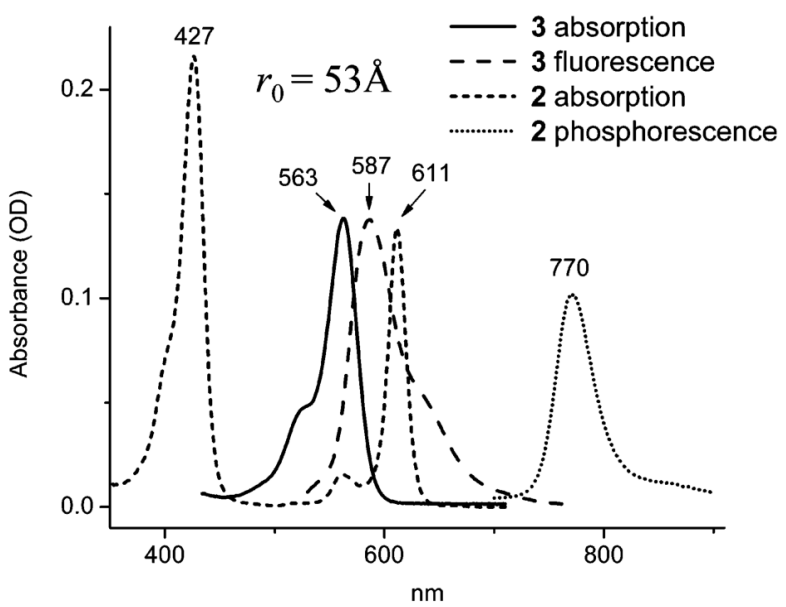

Figure 1.

(left) Functional components of the studied assemblies: meso-tetraaryltetrabenzoporphyrins (TBP, 1-2b); Rhodamine B (RhB) and its functionalized derivatives (3a and 4). (right) Absorption and emission spectra of PtTBP (2) and of $\mathbf{3 a}$ in EtOH. For absorption spectra, the molar ratio of $\mathbf{2}$ and $\mathbf{3 a}$ is 1:1. For emission, solution of $\mathbf{2}$ was purged with Ar; ordinate values are in arbitrary units. 

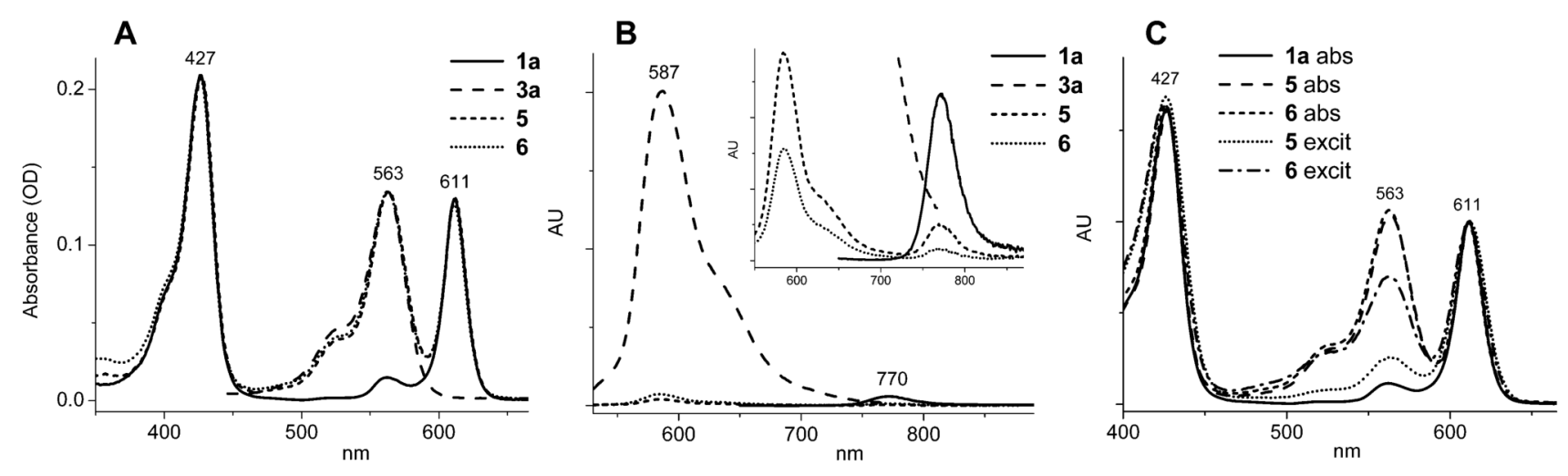

Figure 2.

Absorption (A, C), emission (B), and excitation (C) spectra of adducts 5 and $\mathbf{6}$ and reference compounds 1a and 3a in EtOH. All measurements were performed in deoxygenated solutions. (A) Samples contain compounds in equal molar concentrations. (B) The emission spectra were normalized by the absorbance at $\lambda_{\mathrm{ex}}=520 \mathrm{~nm}$. Inset: enlarged graph. (C) Excitation spectra were recorded for $\lambda_{\mathrm{em}}=770 \mathrm{~nm}$. 


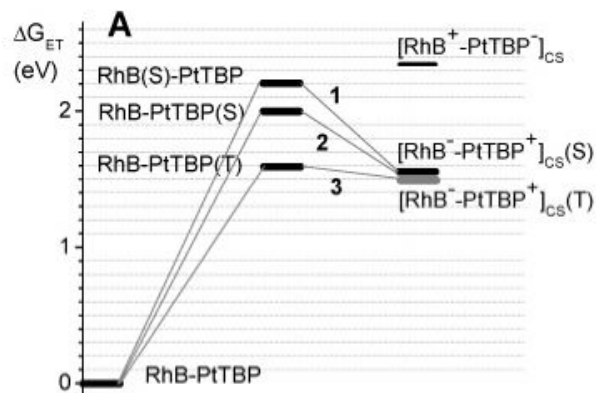

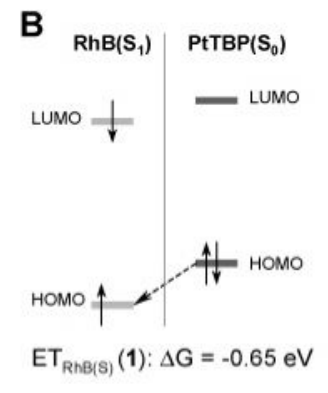

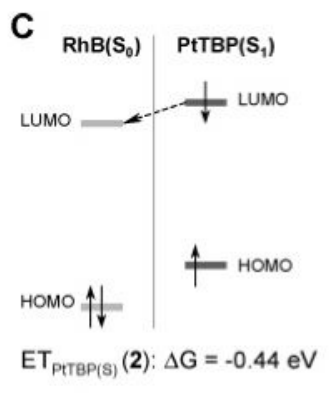

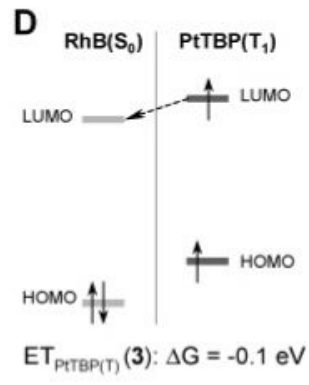

Figure 3.

Energy diagram of electron-transfer pathways in photoexcited RhB-PtTBP adducts (A) and frontier orbital levels corresponding to $\mathrm{ET}_{\mathrm{RhB}(\mathrm{S})}(\mathrm{B}), \mathrm{ET}_{\mathrm{PtTBP}(\mathrm{S})}(\mathrm{C})$, and $\mathrm{ET}_{\mathrm{PtTBP}(\mathrm{T})}(\mathrm{D})$. 


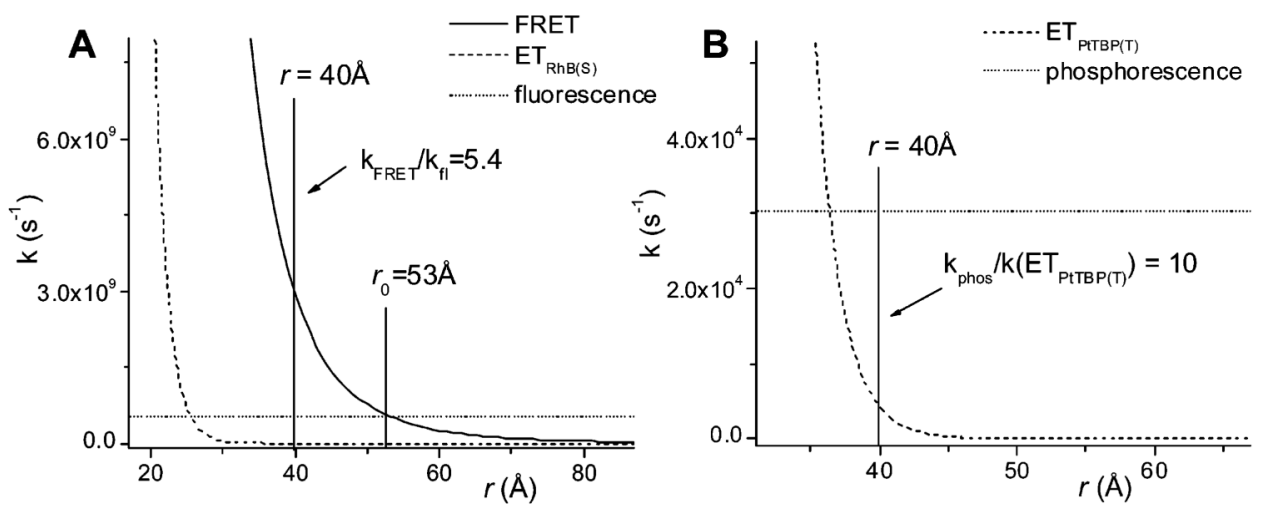

Figure 4.

Calculated distance dependences of FRET, $\mathrm{ET}_{\mathrm{RhB}(\mathrm{S})}(\mathrm{A})$ and $\mathrm{ET}_{\mathrm{PtTBP}(\mathrm{T})}(\mathrm{B})$, in RhB-PtTBP systems. 


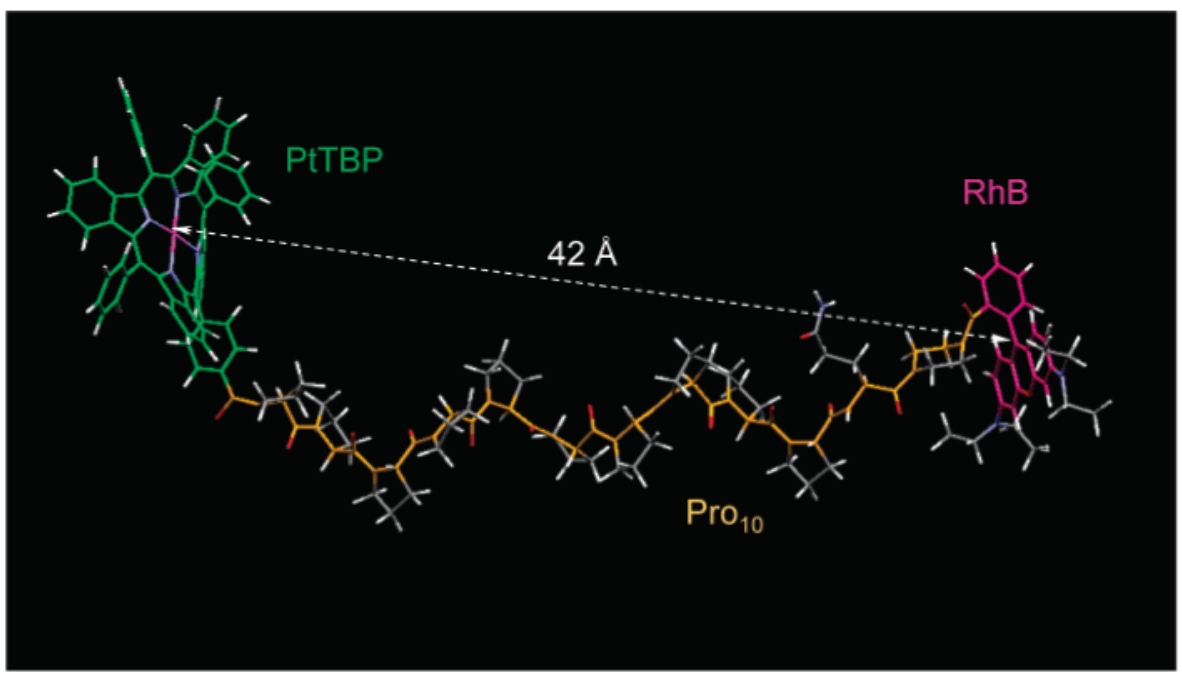

Figure 5.

Optimized structure of RhB-Pro 10 -PtTBP (MM+ force field). Decaproline spacer in its trans conformation provides separation of $42 \AA$ between RhB and PtTBP chromophores. 

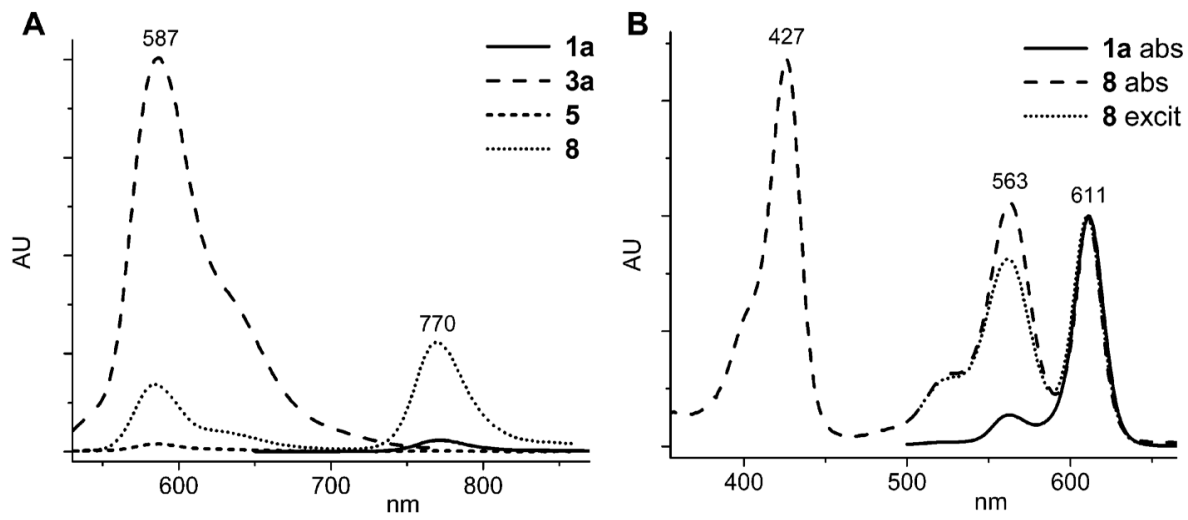

Figure 6.

Emission (A), excitation (B), and absorption (B) spectra of adduct $\mathbf{8}$ and spectra of reference compounds 1a, 3a, and $\mathbf{5}$ in EtOH. All measurements were performed in deoxygenated solutions. (A) The emission spectra were normalized by the absorbance at $\lambda_{\mathrm{ex}}=520 \mathrm{~nm}$. (B) Excitation spectra were recorded for $\lambda_{\mathrm{em}}=770 \mathrm{~nm}$. Absorption and excitation spectra were normalized by the intensity at $611 \mathrm{~nm}$ (lowest energy $\mathrm{S}_{1}$ state), which gives rise to the emitting $\mathrm{T}_{1}$ state. 

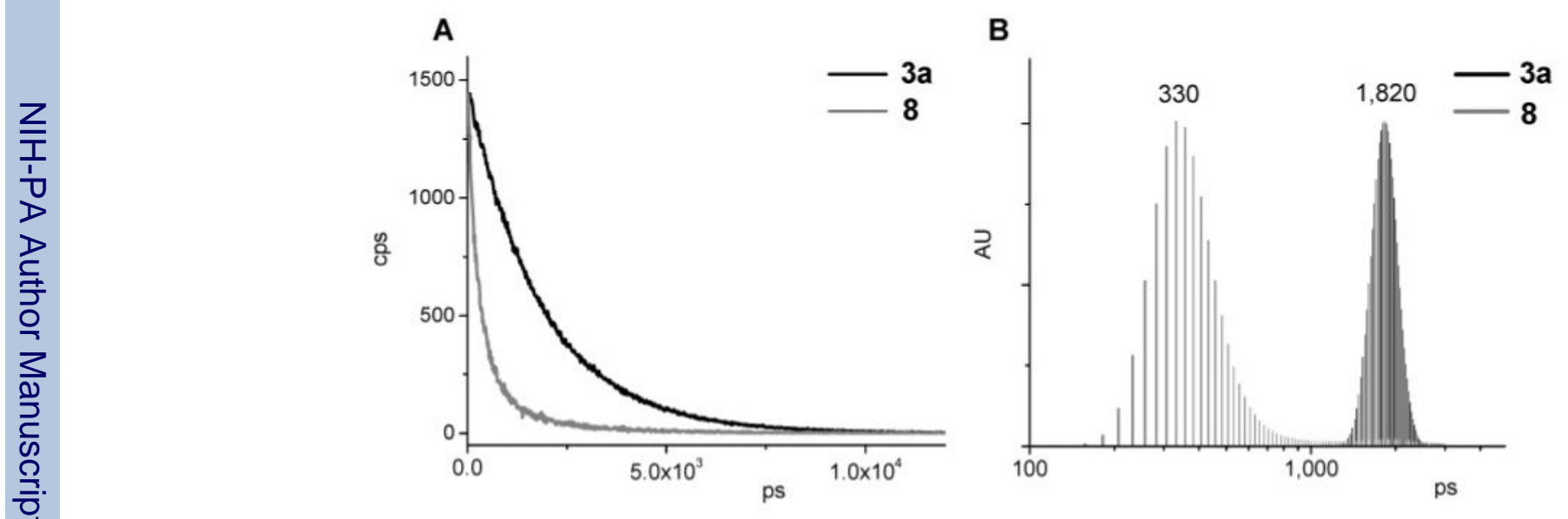

Figure 7.

Fluorescence decays of adduct 8 and reference RhB 3a in MeOH/THF $=1: 1, \lambda_{\mathrm{ex}}=532 \mathrm{~nm}$ (A), and corresponding lifetime distributions (B), obtained by the MEM. 


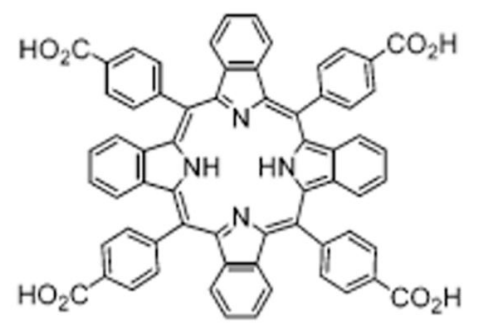

10

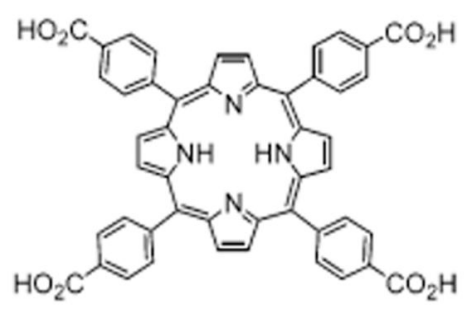

11

Figure 8.

Fluorescent free-base porphyrins used to evaluate 2PA cross sections of $\mathrm{Pt}$ tetraaryltetrabenzoporphyrins $\mathbf{1}$ and $\mathbf{2}$. 

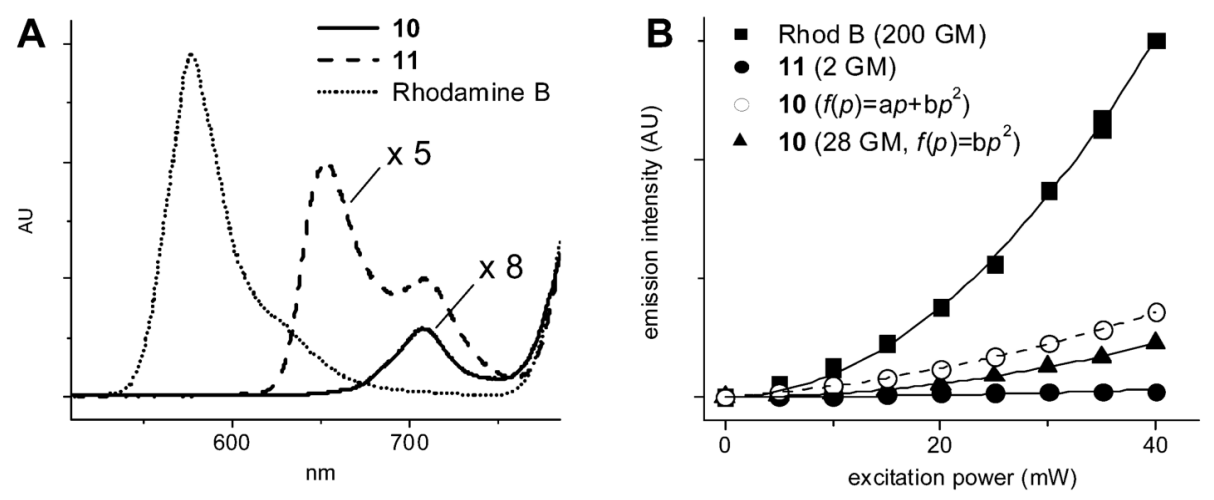

Figure 9.

Fluorescence spectra of 10, 11, and reference Rhodamine B (A) upon excitation at $840 \mathrm{~nm}$ (110 fs). Spectra are normalized by molar concentrations. 10 and 11 were dissolved in $10 \mathrm{mM}$ phosphate buffer in the presence of $1 \% \mathrm{BSA}, \mathrm{pH} \sim 8.5$. Rhodamine B was dissolved in EtOH. To obtain power dependences (B), integral intensities of fluorescence were normalized by molar concentrations and fluorescence quantum yields. For $10(\circ)$, the plot was fit to a secondorder polymonial, and the linear component was subtracted to render the pure quadratic dependence $(\boldsymbol{\Delta})$. 

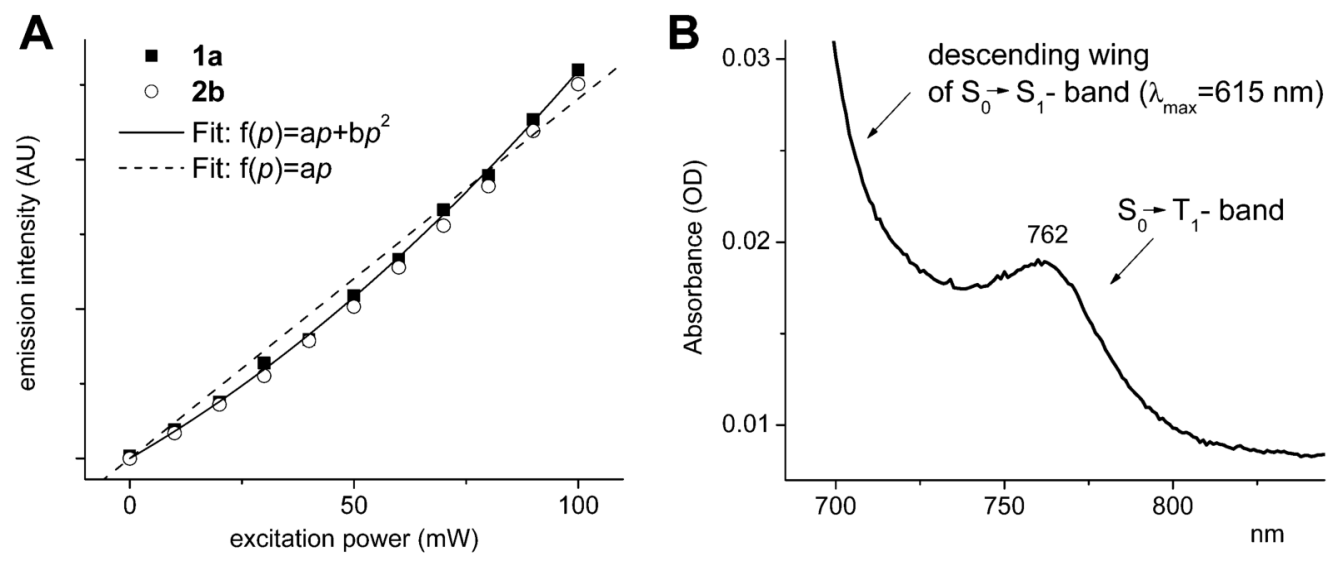

Figure 10.

(A) Power dependence plots of the phosphorescence of $\mathbf{1 a}$ and $\mathbf{2} \mathbf{b}$ in deoxygenated DMF upon excitation at $820 \mathrm{~nm}(30 \mathrm{fs}, 1 \mathrm{kHz})$. (B) $\mathrm{S}_{0} \rightarrow \mathrm{T}_{1}$ linear absorption band in the spectrum of 2b: $\lambda_{\max }=762 \mathrm{~nm}, \epsilon=120 \mathrm{M}^{-1} \mathrm{~cm}^{-1}$. 

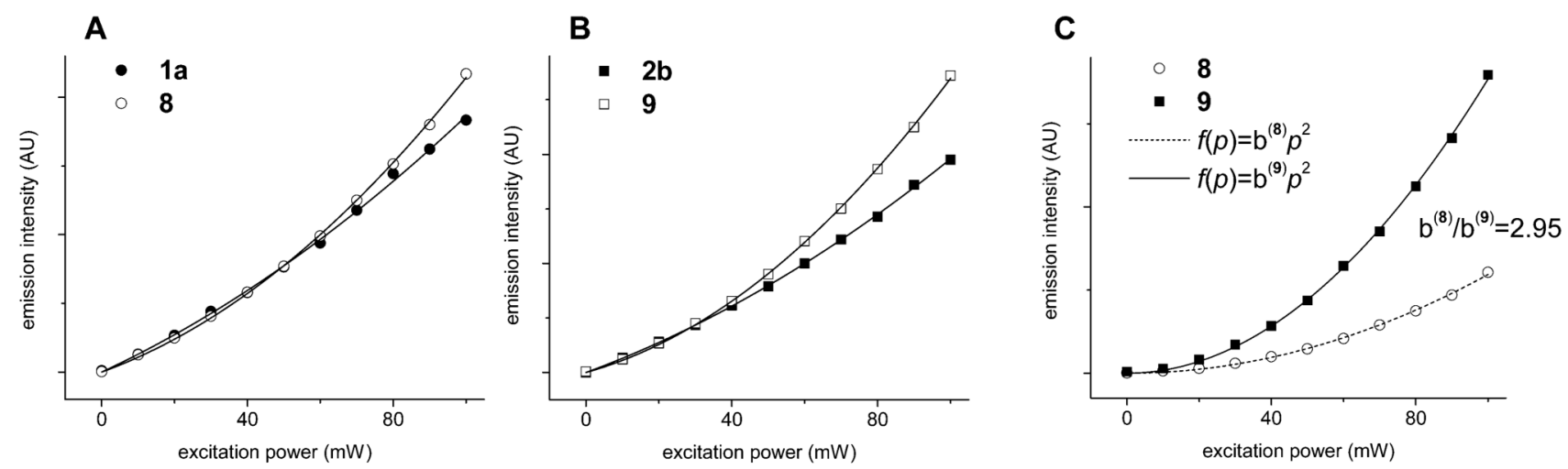

Figure 11.

Phosphorescence power dependence plots of adducts $\mathbf{8}$ and $\mathbf{9}$ and of reference porphyrins 1a and $\mathbf{2 b}$ in deoxygenated DMF upon excitation by $30 \mathrm{fs}$ pules $\left(\lambda_{\mathrm{ex}}=820 \mathrm{~nm}, 1 \mathrm{kHz}\right)(\mathrm{A}, \mathrm{B})$. Emission decays were integrated to give the intensity for each excitation power. The plots were normalized by molar concentrations and quantum yields. (C) Quadratic components of the plots for $\mathbf{8}$ and $\mathbf{9}$, obtained by fitting the raw data (A and $\mathrm{B}$ ) with second-order polynomial and subtracting the obtained linear components. The fits are shown by dashed (8) and solid (9) lines, yielding the amplification ratio of 2.95 . 


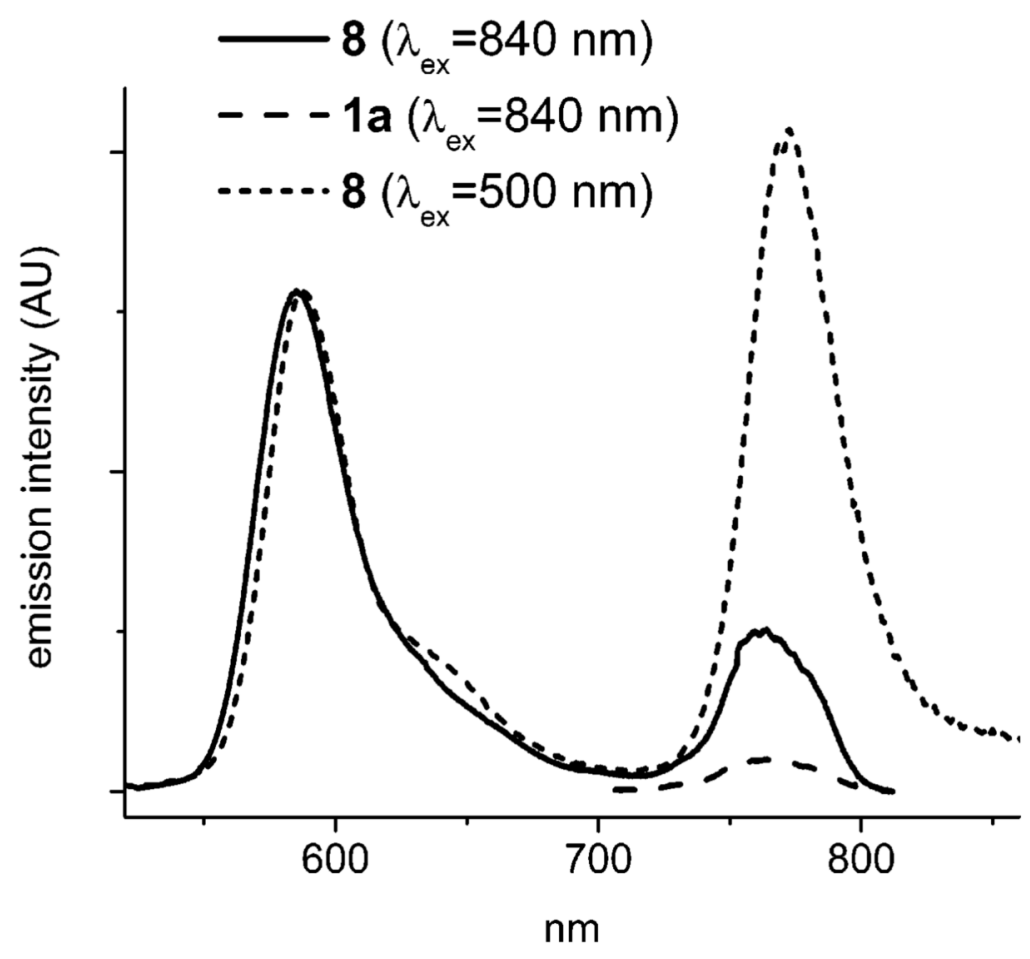

Figure 12.

Emission spectra of adduct $\mathbf{8}$ and porphyrin 1a in deoxygenated DMF upon 2P excitation $\left(\lambda_{\mathrm{ex}}=840 \mathrm{~nm}, 110 \mathrm{fs}, 76 \mathrm{MHz}\right)$. The spectra were normalized by molar concentrations and corrected to remove the residual excitation leak. The emission spectrum of $\mathbf{8}$ upon linear excitation $\left(\lambda_{\mathrm{ex}}=500 \mathrm{~nm}\right)(---)$ was scaled to match the $2 \mathrm{PA}$-induced $\mathrm{RhB}$ fluorescence $\left(\lambda_{\max }\right.$ $=587 \mathrm{~nm})$. 

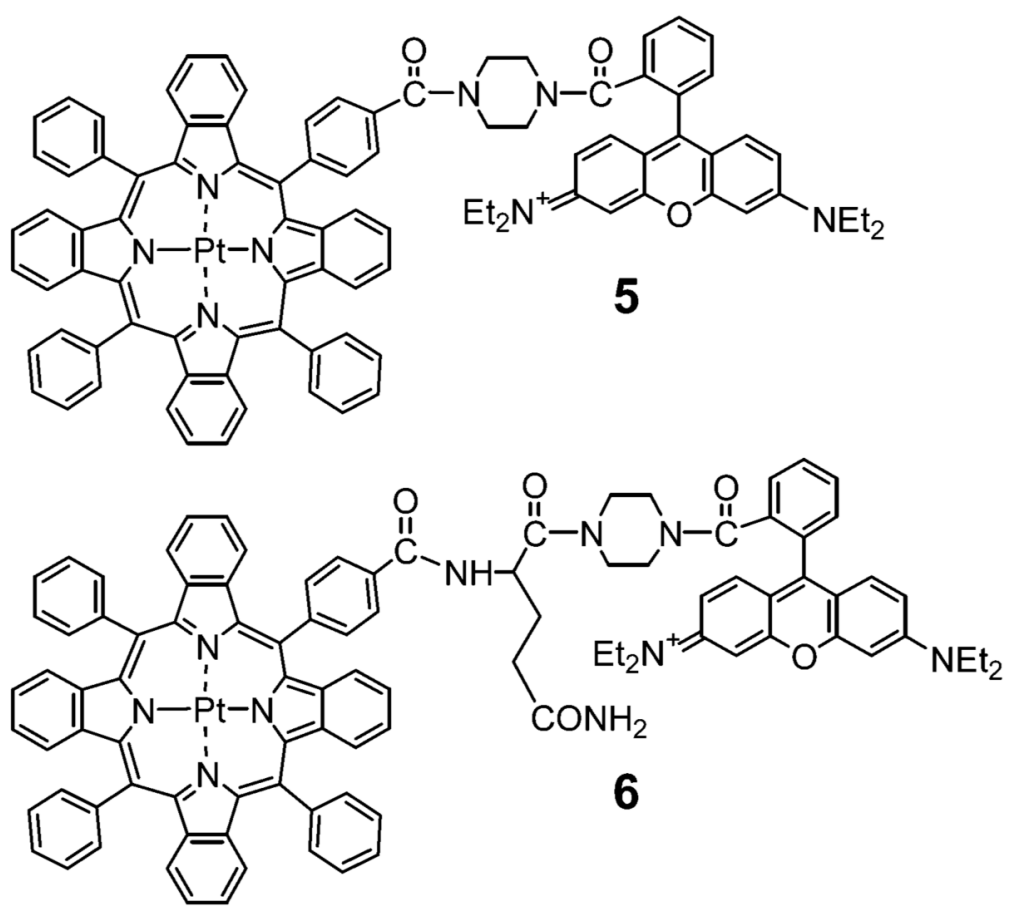

SCHEME 1.

RhB-PtTBP Adducts with Short Spacers 


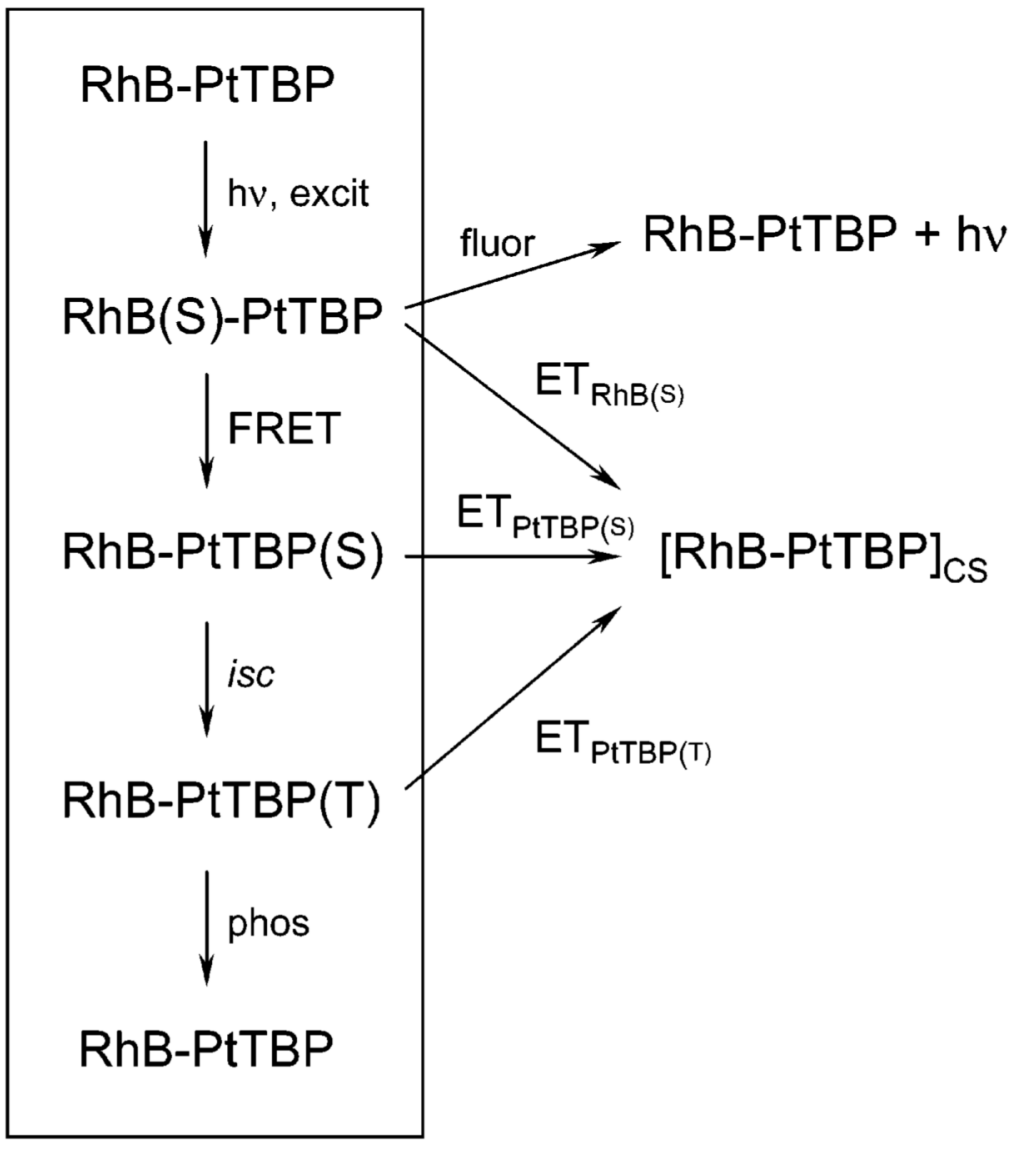

SCHEME 2.

Energy-/Electron-Transfer Pathways in RhB-PtTBP Adducts 

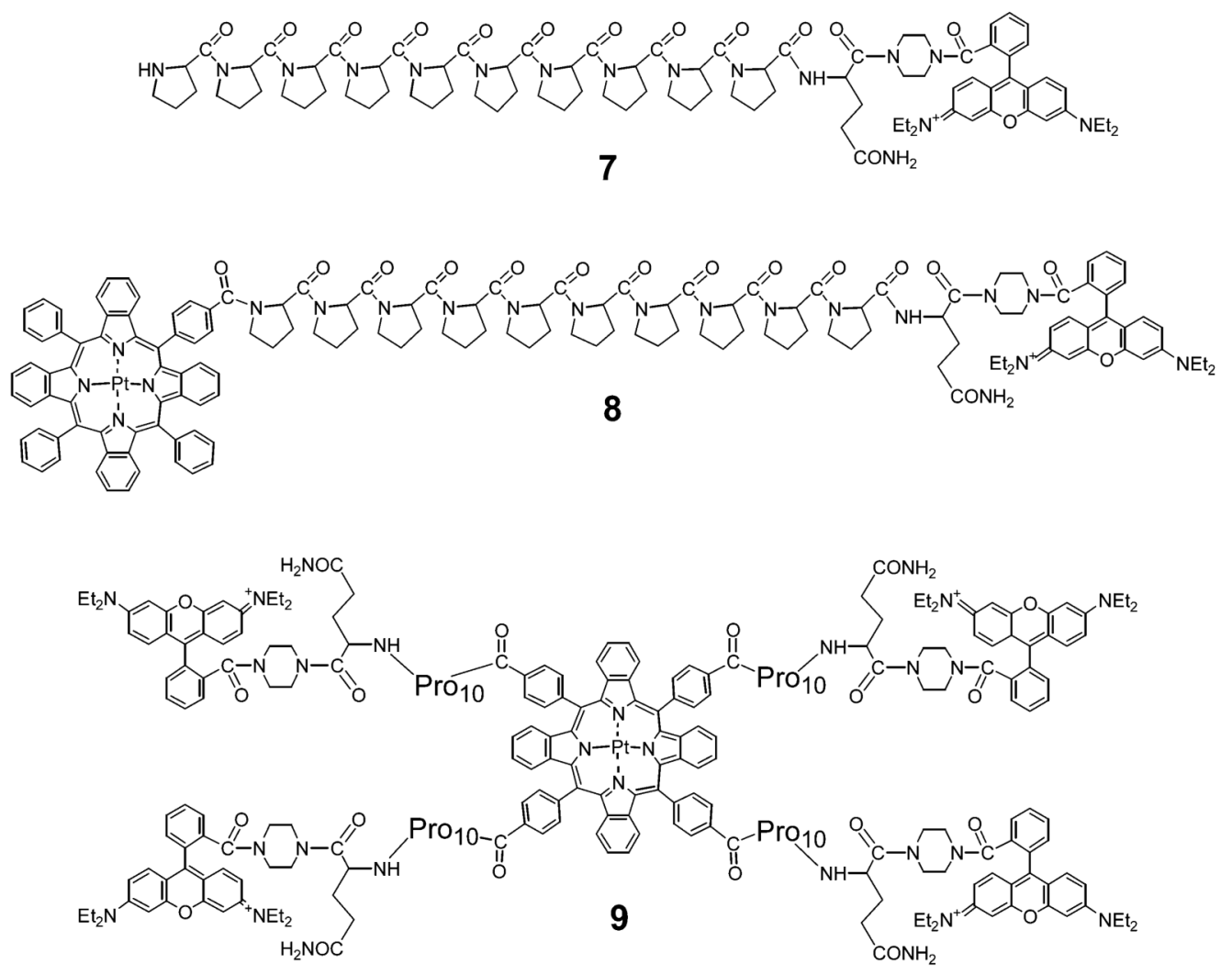

SCHEME 3.

PtTBP-RhB Adducts with Decaproline $\left(\mathrm{Pro}_{10}\right)$ Spacers 


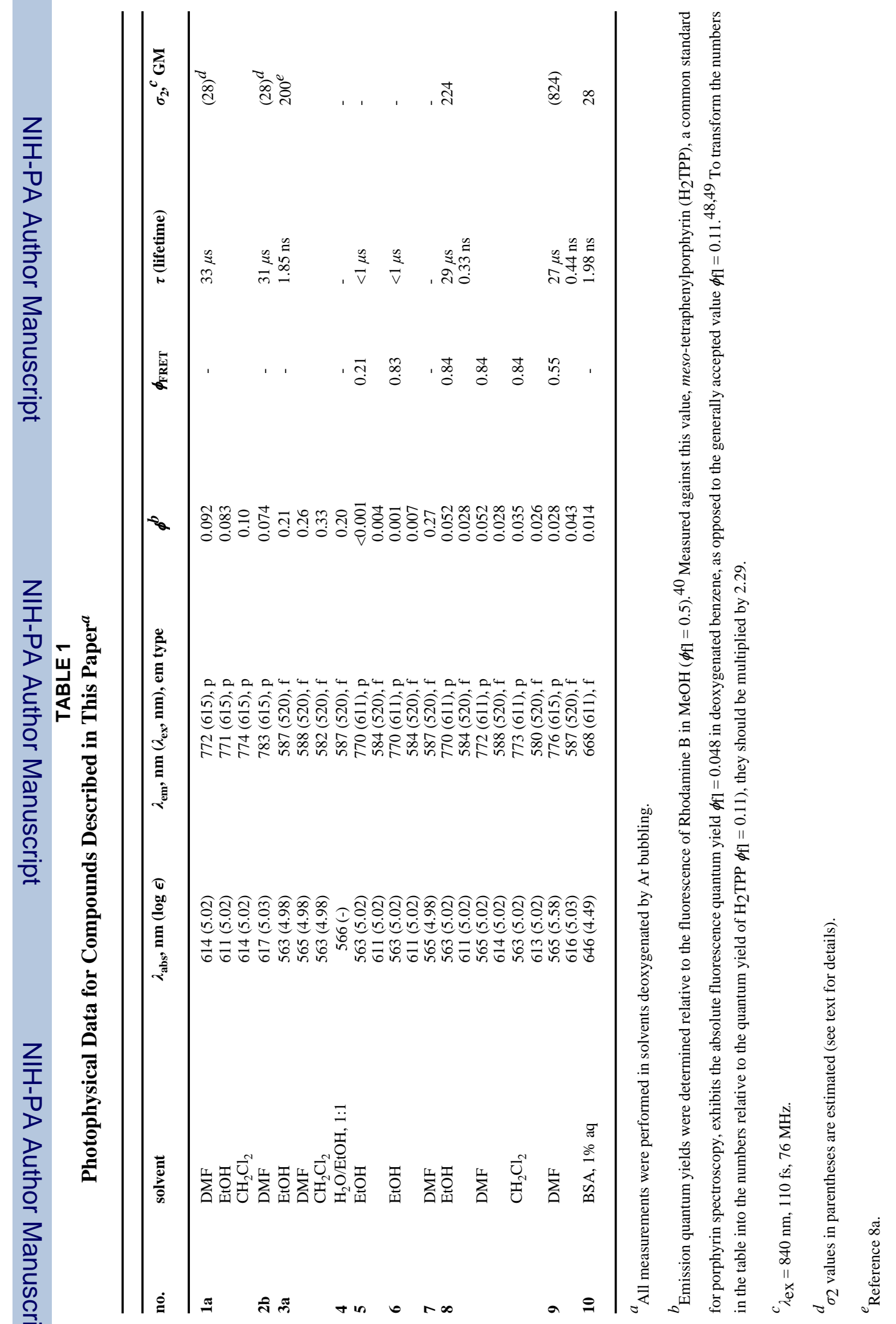

